

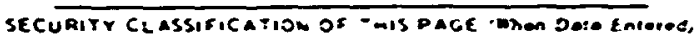

\begin{tabular}{|c|c|}
\hline REPORT DOCUMENTATION PAGE & $\begin{array}{l}\text { READ INSTRUCTIONS } \\
\text { BEFORE COKPLETISC FORM }\end{array}$ \\
\hline $\begin{array}{ll}\text { AEOSAT MIJOBEA } & 2 \text { GOV: ACCESSIOM No } \\
\text { NRL Report } 8677 & \text { :An. A/26 }\end{array}$ & 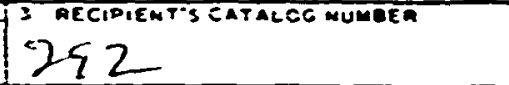 \\
\hline $\begin{array}{l}\text { TITLE (and Swbittos) } \\
\text { LOW-FREQUENCY ACOUSTIC SOURCE LEVELS OF } \\
\text { LARGE MERCHANT SHIPS }\end{array}$ & 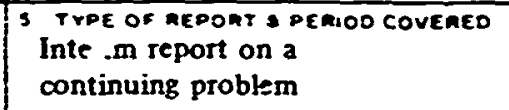 \\
\hline & T- DERFORMINC OAL REDOAT MUMAER \\
\hline $\begin{array}{l}\text { AuTwOA(o) } \\
\text { Evan B. Wright and John Cybulski (deceased) }\end{array}$ & 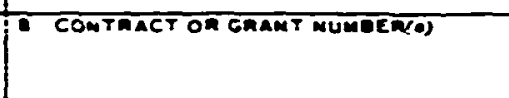 \\
\hline $\begin{array}{l}\text { Fenfonuimc onsanization wame Ams aseness } \\
\text { Naval Research Laboratory } \\
\text { Washington, DC } 20375\end{array}$ & 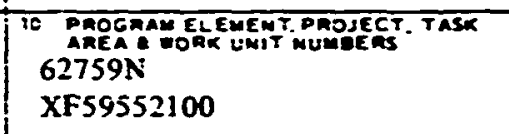 \\
\hline $\begin{array}{l}\text { 11. COMTnostum CFFice wame amd adoness } \\
\text { Naral Eiectronic Systems Command } \\
\text { Washington, DC }=0360\end{array}$ & \begin{tabular}{|l|}
2 MEDOAT DATE \\
March 14, 1983 \\
35 \\
\end{tabular} \\
\hline 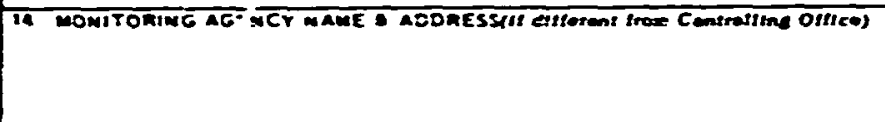 & 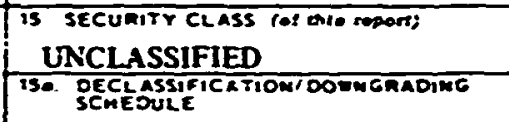 \\
\hline \multicolumn{2}{|l|}{ 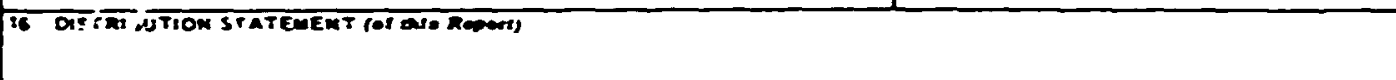 } \\
\hline \multicolumn{2}{|l|}{ 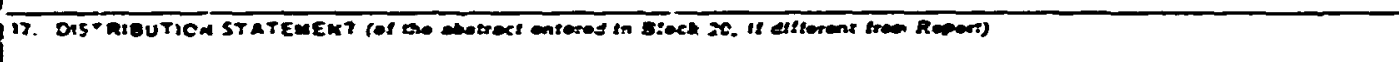 } \\
\hline \multicolumn{2}{|l|}{ 19. SUPPLEMEMTAMY MDTES } \\
\hline \multicolumn{2}{|l|}{ 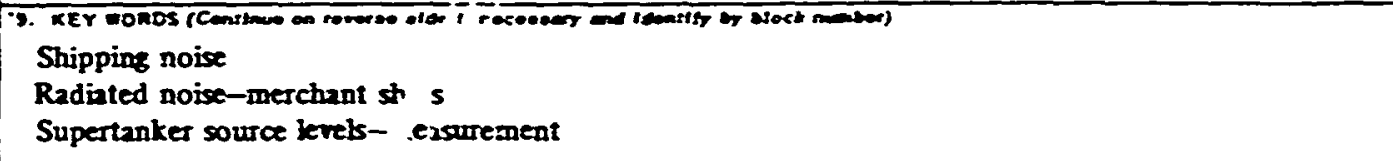 } \\
\hline \multicolumn{2}{|c|}{ 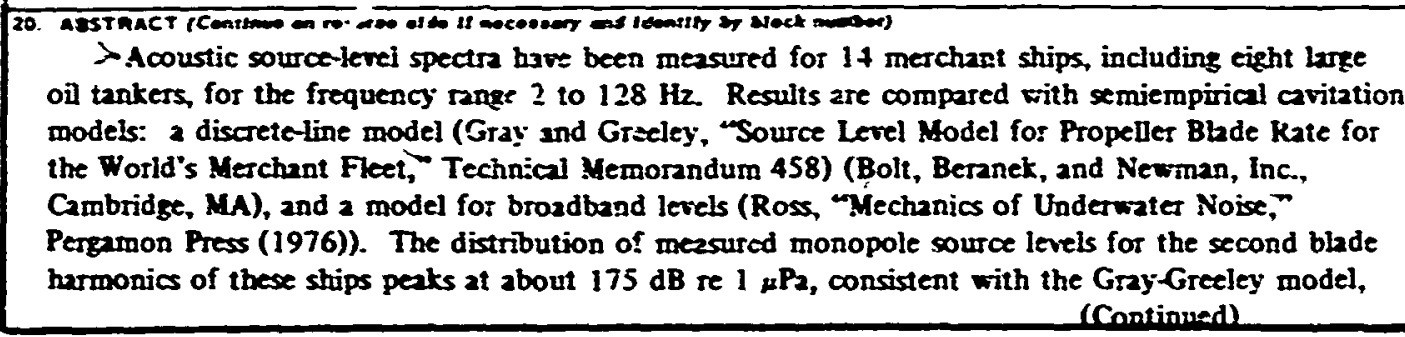 } \\
\hline
\end{tabular}




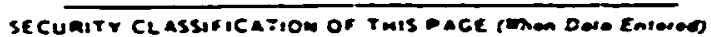

20 ABstract (Cossinued)

$>$ and individual levels agree within the 6 to $8 \mathrm{~dB}$ variance implied by the nodel. Measured levels in the continuum, at 50 and $100 \mathrm{~Hz}$, average 167 and $161 \mathrm{~dB}$ re $1 \mu \overline{\mathrm{P}}_{2}$, respectively, about $6 \mathrm{~dB}$ below the levels predicted by the Ross model. Below $15 \mathrm{~Hz}$, measured line ard broadband levels increase at about $8 \mathrm{~dB}$ per octave of decreasing frequency, a systematic difference from cavitation model predictions. Ttis is possibly caused by hull reradiation effects, suggesting a low-freauenc: limi for the valiaity of a point-source model for these lange ships. Th's report includes a set of broadside source-leve! spectra at several ranges for each ship, and tables of ship characteristics and engineerirg data. These acoustic measurements and the associated data comprise a data bank suitable for further study of ship-generzted noixe. 


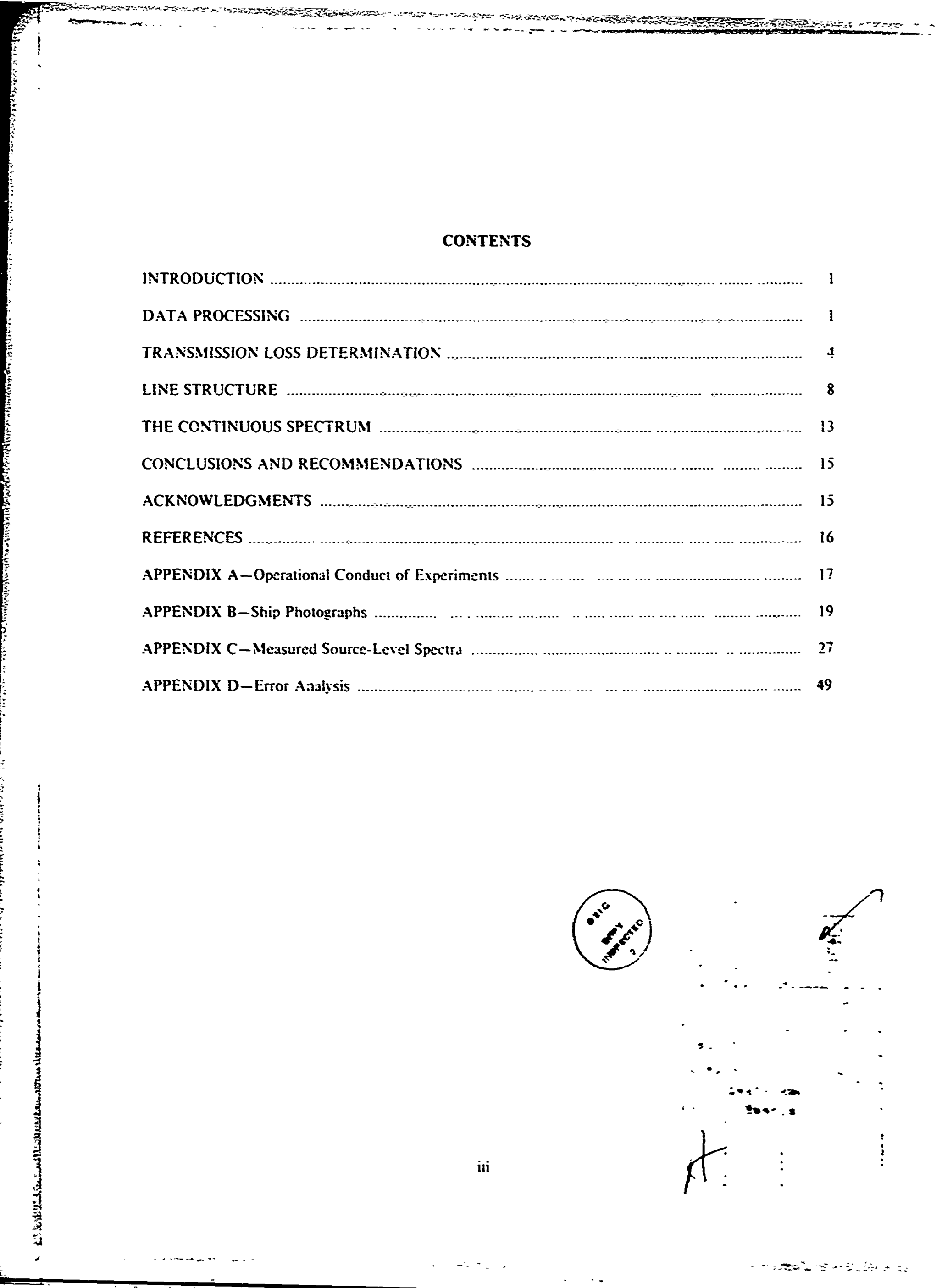




\section{LOW-FREQUENCY ACOUSTIC SOURCE LEVELS OF LARGE MERCHANT SHIPS}

\section{INTRODUCTION}

The importance of shipping noise as a contributor to ambient noise levels in the scean has long been recognized. In the ast two decades. increases in the amount of shipping. and changes in engineering characteristics of the world's merchani fleet have combined to make shipping noise levels higher than ever before. As stied by Ross. ... one must conclude that in the last 25 years ambient noise has probably risen about $10 \mathrm{~dB}$ in those areas where shipping soise dominates. furthermore. sinip noise musi now have become a dominant factor in some areas where it did not previously control [!].

Models of surface-shipping noise must take into account the newer and larger merchant ship tyos. such as supertanters. since these ships can be expected to be prime contributors to ambient noise levels in areas where they operate. To get reliable data as input to such models. the Naval P.esearch Laboratory conducted two experiments (in 1975 and 1977 ) to measure source-level spectra of large merchani ships [2] In both experiments sonobuoys were deployed in the paths of ships found under way in major shipping lanes in deep water. This report consists of an analysis of the data bbtained from 14 subject ships-half of them supertankers-and comparison of the data with available models of the ship noise spectra.

We believe that this set of noise measurements is a unique data base for large merchant ships The measuremeni geometry was arranged to make the detcrmination of source-receiver range and transmission loss as straightfortard and nearly unambiguous as possible. in each case a row of five sonobuoys. at $926 \mathrm{~m}$ spacing. was air-dropped across the ship's track. The sonobuoy depti was $305 \mathrm{~m}$ Usually the drop was successful in centering the buoy line across th: track, so that there were receivers on eaih side of the shif with ranges at closes! approach (CPA) beiween about 400 and $1306 \mathrm{~m}$. Al these ranges irom the source. sound reception incontaminated by either bottom reflections or Lloyd's mirror interference fringes. for the frequency range 2 to $12 \mathrm{SHz}$. could be achiex $\mathrm{d}$. Appendix $A$. which is extracted from Ref. 2. describes the conduct of the aircraft operations and sound recording in more detail.

The data base consisis of a sat of 145 -channel acoustic recordinzs. each about 20 min long. and also a fairly complete set of acoustically important engineering parameters for ine subject ships. Each ship was identified. and in most cases the operaiing companies responded to inquiries with information about ship dimensions. propeller characteristics. and operating conditions at the time of obsertainn. Table 1 summarizes the experimenial parameters and the operating characteristies foi each ship. Appendix B contains photographs of severai of the ships at the time of measure.nent. Table 2 is 3 summary of the mieasured source ievels for the n̂rst three blade frequencies and broadband tevcls for two selected frequencies in the continuum.

\section{DATA PROCESSING}

The zcoustic recordings were initially digitized ai a frequency resolution of 1117 . with 754 overlap: i.e.. spectra representing 1 s of integration time were gencrated at intervals of $1 / 4 \mathrm{~s}$. A hardware fast Fourier transform with Hanning tapering was used in this initial stage. The digital data base thus

Manuscripi appoved December s, 19s? 
WRIGHT AND CYBULSKI

Table 1 - Characteristics of Subject Ships

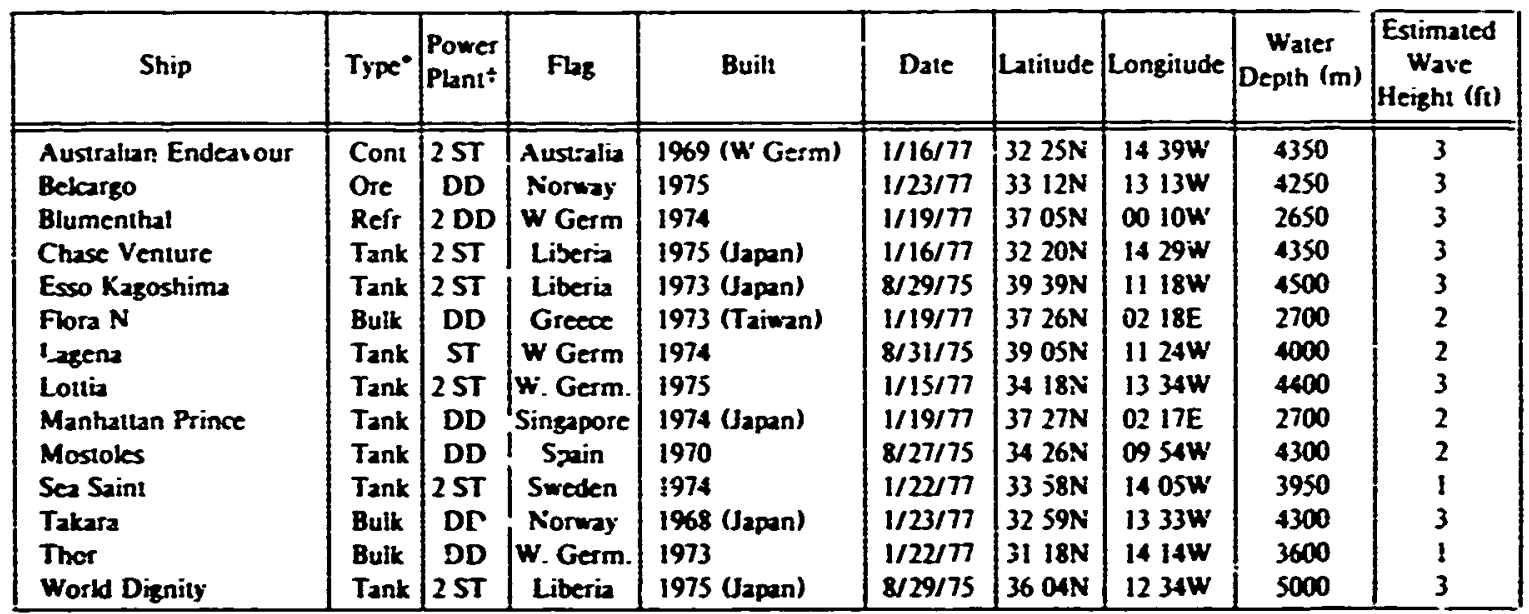

- Cont : High-Speed Container Ship

Ore : Ore Cargo Ship

Refr : Refrigerated Cargo Ship

Tank : Oil Tanker

Bulk : Bulk Carzo Ship

+ ST : Steam Turbine

DD : Direct-Drive Diesel

Table 1 - Characteristics of Subject Ships (Continued)

\begin{tabular}{|c|c|c|c|c|c|c|c|c|c|c|}
\hline Ship & Course & $\begin{array}{c}\text { Speed } \\
(k t)\end{array}$ & $\mathrm{rpm}$ & $\begin{array}{c}\text { Tonnage } \\
\text { (1000 DWT) }\end{array}$ & $\begin{array}{l}\text { Length } \\
\text { (m) }\end{array}$ & $\begin{array}{l}\text { Beam } \\
\text { (m) }\end{array}$ & $\begin{array}{l}\text { Draft } \\
\text { (m) }\end{array}$ & $\begin{array}{c}\text { Shaît } \\
\text { Depih (m) }\end{array}$ & $\begin{array}{c}\text { Propelles } \\
\text { Diameier (m) }\end{array}$ & Blades \\
\hline Austratian Endearour & 199 & 20.0 & 122 & 14 & 217 & 29 & 10.0 & 6.2 & 63 & 4 \\
\hline Beleargo & 045 & 15.0 & 111 & 109 & 266 & 38 & 13.9 & 9.9 & 6.8 & 4 \\
\hline Blumenthal & 259 & 19.7 & 128 & 12 & 146 & 22 & 9.5 & 4.5 & 6.0 & 4 \\
\hline Chase lenture & 199 & 11.9 & 31 & 280 & 340 & 53 & 21.6 & 4.1 & 8.6 & 5 \\
\hline Esso Kagoshima & 022 & 14.5 & 83 & 257 & 338 & 52 & 20.3 & 14.4 & 9.2 & 5 \\
\hline Flora $\mathbf{N}$ & 251 & 13.6 & 117 & 29 & 181 & 25 & 10.4 & 4.6 & 6.0 & 4 \\
\hline Lagena & 019 & 14.6 & 78 & 312 & 351 & $5 s$ & 22.1 & 15.2 & 9.2 & 4 \\
\hline Loltia & 177 & 15.5 & 72 & 317 & 321 & 56 & 12.3 & 58 & 9.2 & 4 \\
\hline Manhattan Prince & 085 & 162 & 107 & 85 & 245 & 38 & 13.7 & 8.0 & 60 & 5 \\
\hline Mostoles & 042 & 12.6 & 114 & 103 & 266 & 39 & 196 & 14.6 & 63 & 4 \\
\hline Sea Saint & 197 & 13.2 & 66 & 356 & 302 & 60 & 13.1 & 7.1 & 91 & 5 \\
\hline Takara & 015 & 13.1 & 108 & $5 ?$ & 224 & 32 & 11.6 & 76 & 5.9 & 5 \\
\hline Thor & 190 & 155 & 100 & 146 & 303 & 43 & 122 & 79 & 7.4 & 7 \\
\hline World Dignity & 022 & 177 & S6 & 271 & 337 & 54 & 210 & 130 & 86 & 5 \\
\hline
\end{tabular}


Table 2 - Summary of Experimental Results

\begin{tabular}{|c|c|c|c|c|c|c|c|c|c|c|c|c|c|}
\hline \multirow[t]{3}{*}{ Ship } & \multirow{3}{*}{$\begin{array}{l}\text { Estimated } \\
\text { Cavitution } \\
\text { Depih }(m)\end{array}$} & \multicolumn{2}{|c|}{$\begin{array}{c}\text { Measured } \\
\text { CPA Ranges } \\
(\mathrm{m})\end{array}$} & \multicolumn{2}{|c|}{$\begin{array}{c}\text { Measured } \\
\text { Line Frequencies } \\
\left(H_{2}\right)\end{array}$} & \multicolumn{4}{|c|}{$\begin{array}{l}\text { Monopole Blade } \\
\text { Line Levels } \\
\text { (dB re } \mu \mathrm{Pa} \odot \text { (m) }\end{array}$} & \multicolumn{4}{|c|}{$\begin{array}{l}\text { Monopole Broudband } \\
\text { Levels } \\
\text { (dB re } \mu \text { Pa/Hz } 9 \text { Im) }\end{array}$} \\
\hline & & $\mathbf{R}$ & L. & Shaft & Blade & \multicolumn{3}{|c|}{ Measifed } & Model Predictions & \multicolumn{2}{|c|}{ Measured } & \multicolumn{2}{|c|}{ Madel Predictions } \\
\hline & & & & & & $f_{1}$ & $f_{2}$ & $f_{3}$ & $f_{1}, f_{2}, f_{3}$ & $50 \mathrm{~Hz}$ & $100 \mathrm{~Hz}$ & $50 \mathrm{~Hz}$ & $100 \mathrm{~Hz}$ \\
\hline Australien Endeavour & 40 & 473 & 473 & 2.0 & 8.0 & 197 & 185 & 182 & 175 & 172 & 159 & 173 & 169 \\
\hline Belcargo & 7.6 & 472 & $26 ?$ & 1.9 & 7.5 & 189 & 174 & 168 & 176 & 164 & 156 & 17.3 & 169 \\
\hline Blumenthal & 2.4 & 400 & 599 & 2.1 & 8.5 & 185 & 173 & 165 & 175 & 163 & 157 & 174 & 169 \\
\hline Chase Venture & 11 & 470 & - & 1.0 & 5.1 & 197 & 189 & 177 & 175 & 172 & 164 & 165 & 160 \\
\hline Esso Kagoshima & 11.1 & 400 & $\$ 53$ & 1.4 & 6.9 & 196 & 181 & 179 & 182 & 169 & 164 & 174 & 170 \\
\hline Flora N & 2.5 & 390 & 543 & 1.9 & 7.7 & 185 & 186 & 181 & 173 & 170 & 162 & 171 & 16? \\
\hline Lagena & 12.0 & 430 & 518 & 1.3 & 5.2 & 200 & 182 & 174 & 177 & 166 & 161 & 172 & 167 \\
\hline Lottia & 2.6 & 408 & 445 & 1.2 & 4.8 & 197 & 188 & 180 & 176 & 106 & 153 & 170 & 16.9 \\
\hline Manhaltan Prince & 5.9 & 179 & 700 & 1.1 & 8.9 & 190 & 180 & 176 & 176 & 166 & 166 & 170 & 165 \\
\hline Mostoles & 12.4 & 44 & $\$ 44$ & 1.9 & 7.5 & 193 & 175 & 174 & 174 & 166 & 165 & 172 & 167 \\
\hline Sea Suint & 3.9 & 950 & 929 & 1.1 & 5.5 & 192 & 183 & 180 & 178 & 177 & 160 & 168 & 164 \\
\hline Takara & 5.5 & 170 & 635 & 1.7 & 8.6 & 184 & 174 & 170 & 175 & 165 & 160 & 169 & 164 \\
\hline Thor & 5.3 & 273 & 620 & 1.7 & 11.6 & 187 & 173 & 169 & 186 & 161 & 161 & 175 & 171 \\
\hline World Dienity & 100 & 405 & $49 ?$ & 1.4 & 7.2 & 193 & 183 & 178 & 181 & 163 & 161 & 174 & 169 \\
\hline
\end{tabular}

created was used as the input to second-stage Fourier analyses (zoom FFTs) at finer frequency resolutions. Most of the zoom-FFTs, such as those used for the source-level spectra of Appendix C, were done at a frequency resolution of $1 / 4 \mathrm{~Hz}$, in the frequency band 0 to $128 \mathrm{~Hz}$. The finest resolution used, in analyzing blade-line widths, was $1 / 64 \mathrm{~Hz}$. In all cases, a sof:ware FFT with Hanning tapering was used in the zoom processing.

Figure 1 shows typical spectra, in which discrete lines are seen well above the continuum at frequencies up $10100 \mathrm{~Hz}$. The logarithmic plot versus frequency accentuates the periodic nature of the discrete line structure. These spectra satisfy one essential condition for making reliable source-level measurements at all frequencies: the levels rise above background, over the whole band, during time of ship passage. This condition was satisfied for all 14 ships analyzed. The highest curve is a beamaspect spectrum (at CPA); the stern and end spectra are at angles of $82^{\circ}$ and $87^{\circ}$ beyond beam. The $15-\mathrm{dB}$ rise in level as the ship passes was typical for all ships. The lowest curve is a system noise spectrum in the absence of signal, calibrated as a received level for comparison.

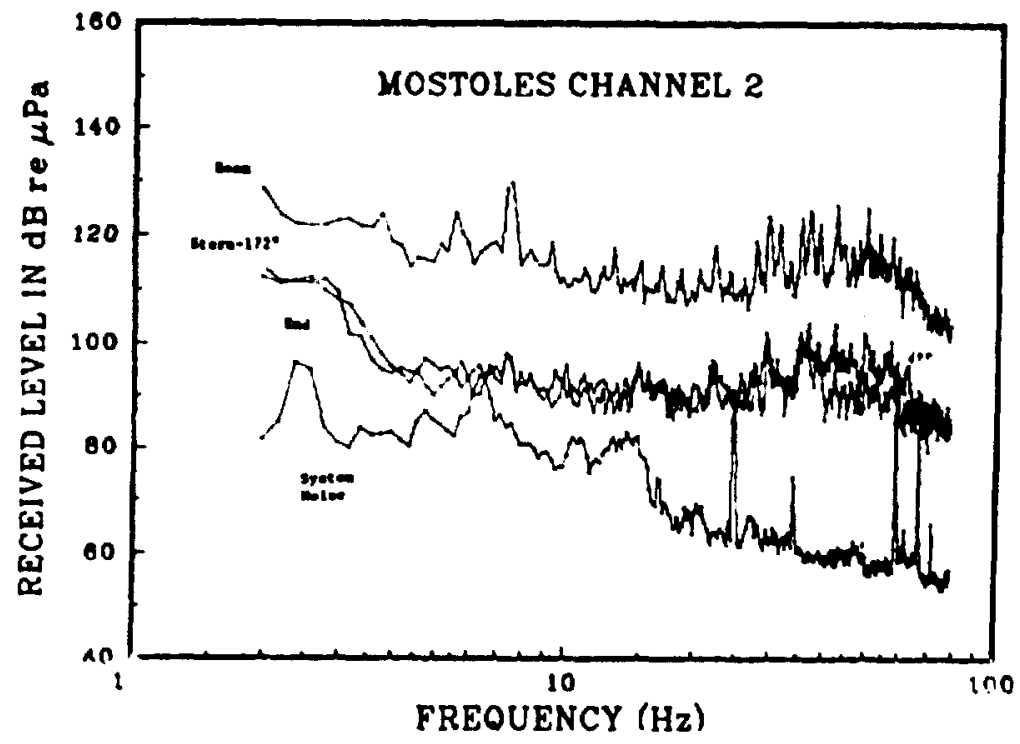

Fig. 1 - Received-level spectra for a large diesel lanker 
The rise in received level is used to esumate the time of the closest approach of the ship (CPA), and to determine between which iwo buoys the ship passed. In Fig. 2, received level versus time for a spectral line (blade-rate line) and for a 1-Hz region of the broadband spectrum are shown. Evidently. the time of CPA can be determined to within $10 \mathrm{~s}$.

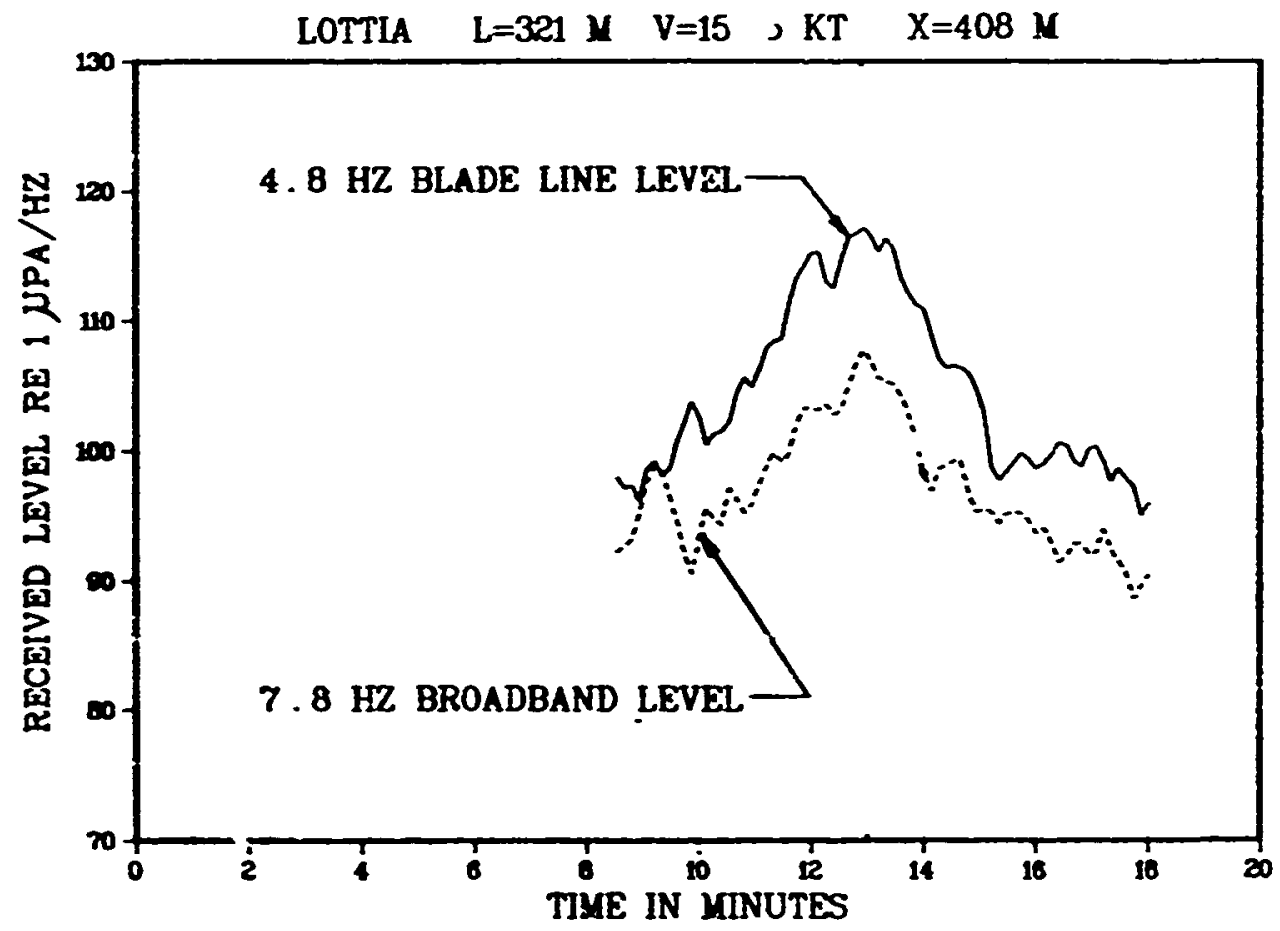

Fis. 2 - Received-kvel time histories for a brge steam-powered lanker. showing the peak al CP.A

\section{TRANSMISSION LOSS DETERMNNATION}

The inertial navigation system of the aircraft was used to track the target ship. and to record the locations of the buoys. Figure 3 shows a typical ship track, with some of the fixes from which the track was estimated. The computed track is a constant-speed thumb line obtained by a least-squares fit to the fixes. The track estimates generally agreed well with uperator reports of course and speed, but they were not accurate enough in relation to the buoy locations to be used for source-receiver ranging. Examination of the acoustic recordings generally showed unambiguously where in the buoy line the ship passed: therefore. we have used the acoustic data for source-receiver ranging. and have based the calculation on the closest receivers to the ship's track: i.e.. those for which bottom returns can be neglected. We assume that the source of radiated noise is propeller cavitation, and that this source is Incalized at a point between the propeller shaft and the top of the propeller disk. This means that all source depths in the measurements were less than about $12 \mathrm{~m}$ below the surface. so that surface interference effects are important. Accordingly. the transmission-loss calculation adopted was a simple isovelocity calculation of the direct and surface-reflected path lengths, and conerent addition of the two rays. The ranging and transmission-loss calculation procedure is summarized as follows:

- Determine the two closest buoys and the CPA times (the ship track data is helpful in determining whether CPA occurred simultaneously at all buoys). 


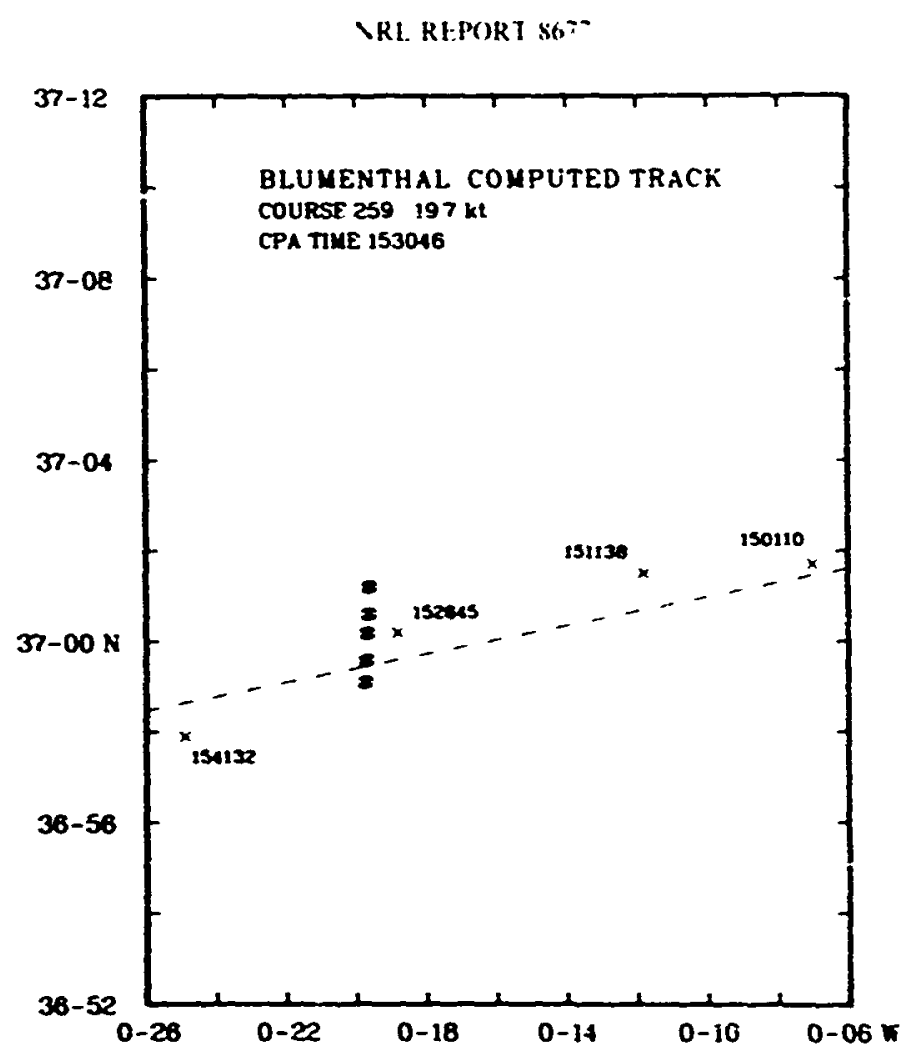

Fis i - A computed ship irack with arcraft tiv lowatrons and buoy iocations

from incitul tusuption dats

- For the two closest receivers. compute the mean received levels for the first three blade lines. Since transmission loss varies approvimately as $40 \mathrm{log} r$. where $r$ is the slant range. preliminary estimates of the two CPA ranges can be made.

- Using these estimates. compute mean source levels for the first three biade lines at the two bioys. Correct the range estimates and repeat the source level computation until these mean levels agree. In each step. a two-minute mean source level aboul CPA is com. puted by calculatung transmission loss separately for 30 locations on the track. 4 s apart in the data record.

This procedure assumes that the blade lines are produced by an omnidirectional point source lwe hate assumed right-left symmetry and no dependence on depression or horizontal aspect angles: the Lloyd mirror dipole pattern is built into the transmission loss calculation). The resultant spectra are for a monopole source at $1 \mathrm{~m}$. One measure of the validity of the assumptions is how will the curves correspond over the whole frequency range, for different baoys. Figures 4 and 5 show some comparisons for buoys within the $200101300 \mathrm{~m}$ range window and give an idea of the variability of the results.

In addition to these source level spectra-essentially broadside measurements-we siow in Figs. $t$ to 9 some polar plots of source level versus horizontal aspect angle for fout blade lines of the Woild Dignity. Cybulski [2] computed these levels from the NRL data by using a wave-theoratic tFi:pl program [3] for transmission-loss determination. and comparing the results obtained when the botiom was assumed to be (a) completely reflecting. and (b) completely absorbing. As the angle from broadstde increases (along with the range from ship to receiver), a point is reached where the lwo Fip calculations differ by more than $6 \mathrm{~dB}$ : at this point the effect of the hollom is assumed in be urs anown and the plot is cut off. For smaller angles the mean of the two transmission-loss calculations is used. In the figures bow aspect is on the positive ordinate axis (top of figurel. and corresponding pairs of 


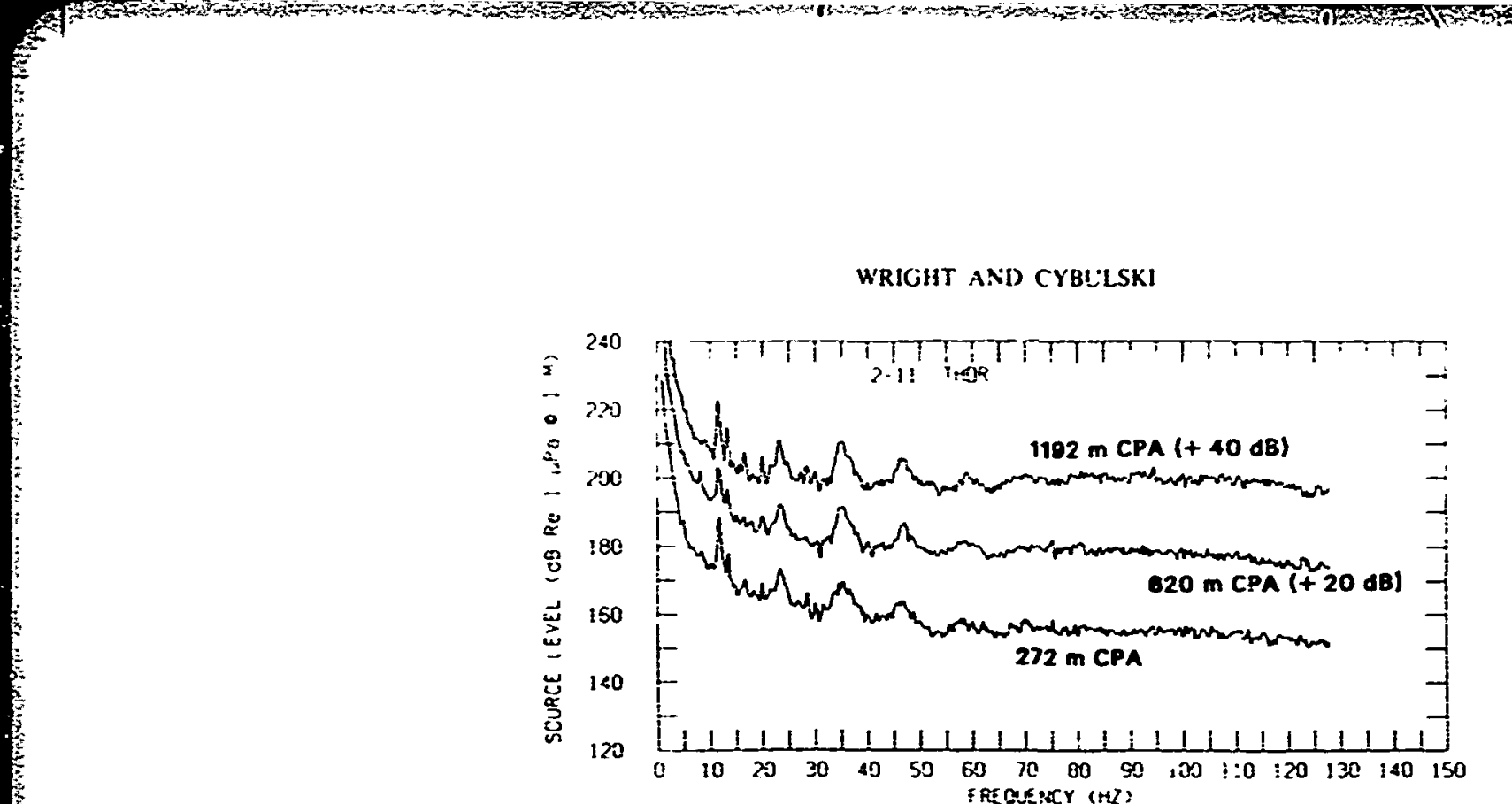

Fig. 4 - Source level spectra for Takara at three CPA ranges

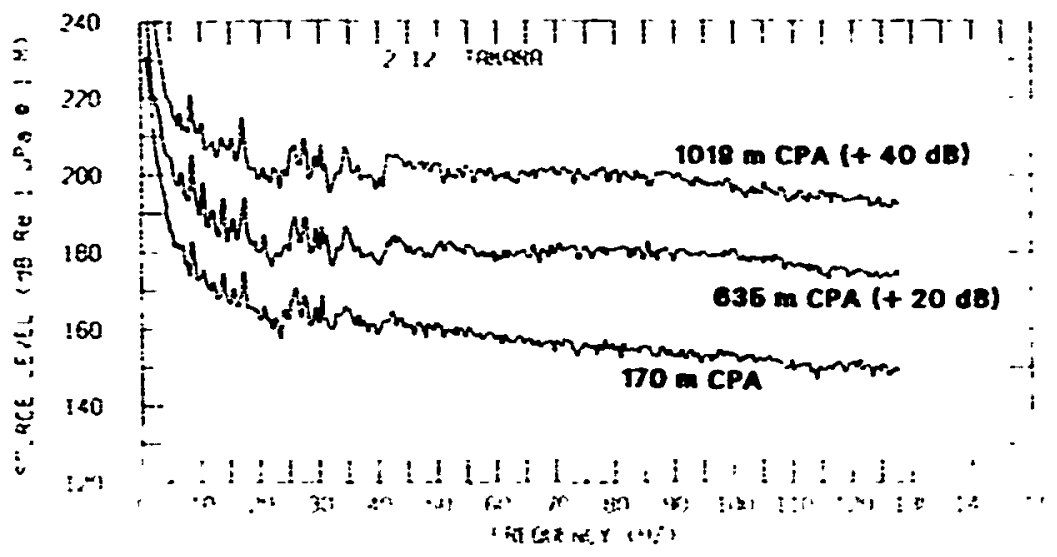

Fig. 5 - Source kevel spectra for Thor at three CPA ranges
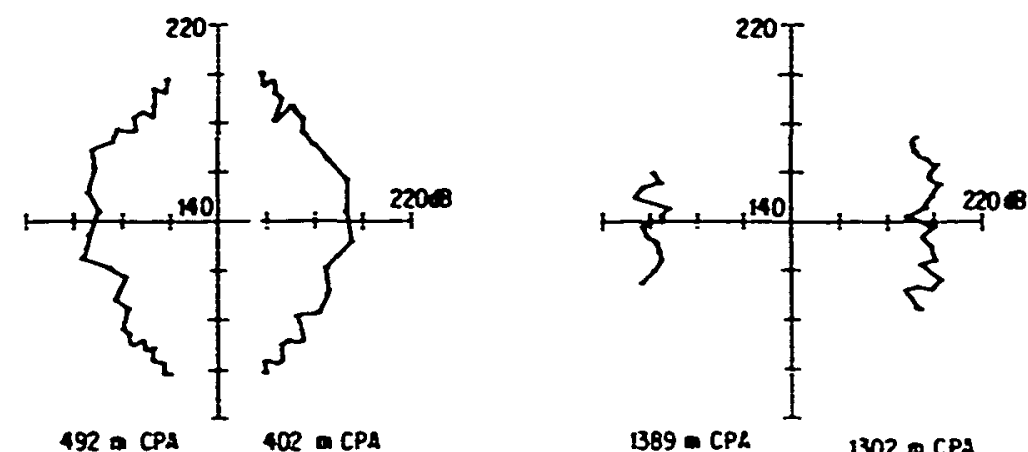

Fiz. 6 - Source ketel directionality for World Dienity blafe fundamental $\left(7.21\right.$ liz $^{2}$ 
IRI RIP(SHI It:-

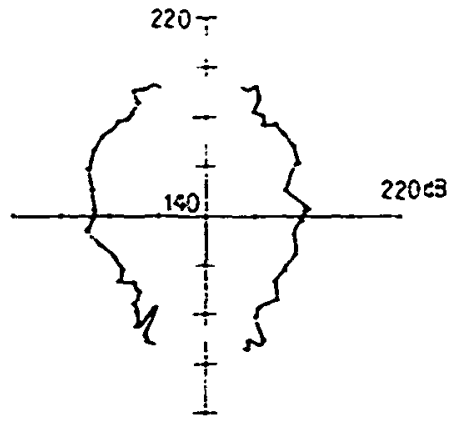

492 a CPS 405 m CPA

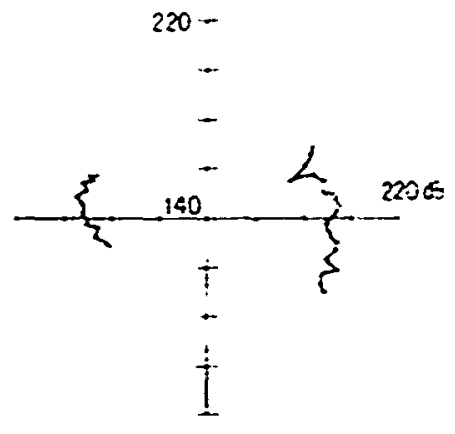

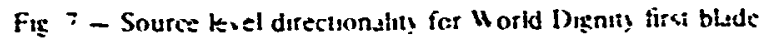
harmonics $11+|| 1 \mid$
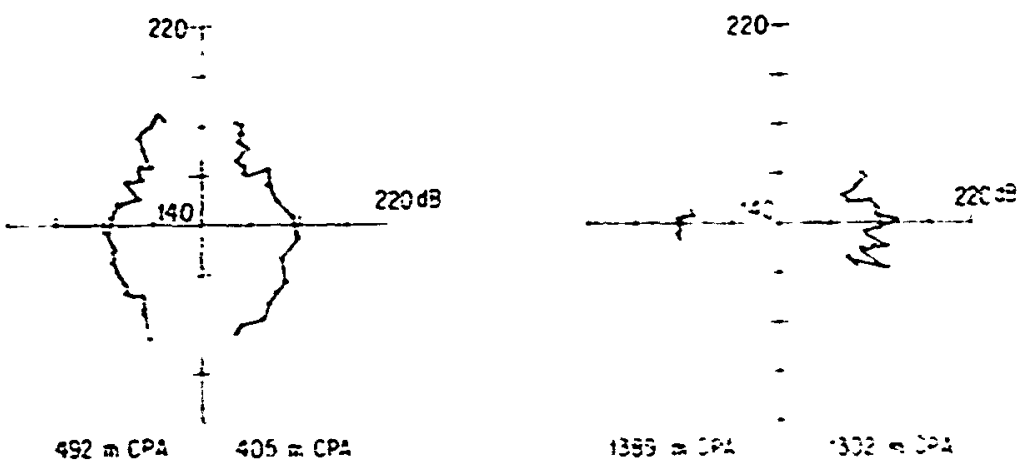

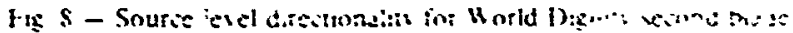
Fe.
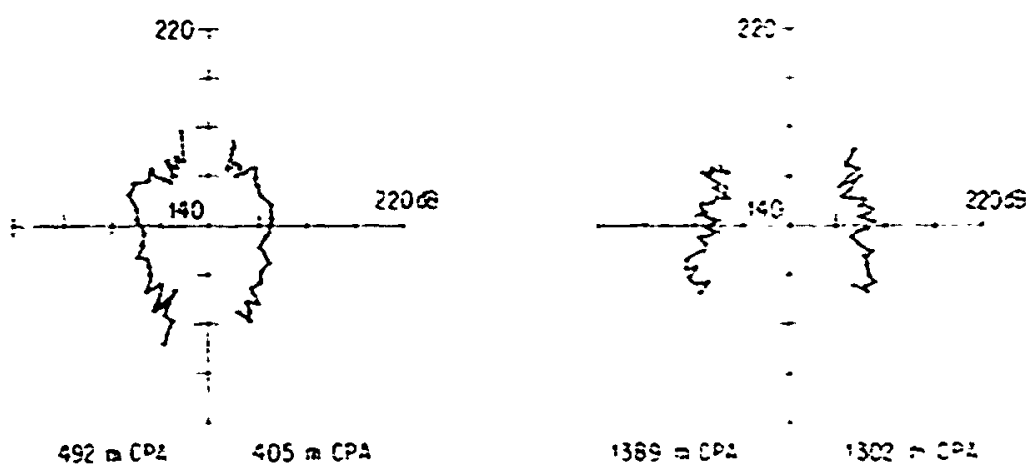

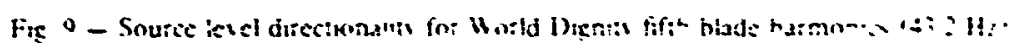




\section{KRIGHT AND CYBLILSKI}

receivers on right and left are plotted together. The plots mostly show increasing leveis for aspec: angles approaching bow and stern but it should be borne in mind that the computed trans nission loss had Lloyd-mirror interference from a perfectly reflecting surface buil in. This condition may not be satisfied for the higher aspect angles because the sh!p's hull gets in the way, or because scattering from the ship's wake and at longer ranges (smaller angles of incidence at the surface) reduces the amplitude of the image source. In any case. the plots show no systematic directionality within the 2-min segment of the data that was used for the broadside source level calculation. This segment includes angles up io about $\pm 53^{\circ}$ from beam aspect for the closest receiver, and up to about $\pm 21^{\circ}$ for the farthest.

Appendix $D$ is an outline of an error analysis of the procedure. Estimates of errors in the parameters used in the calculation are used in propagation-of-error formulas to estimate the uncertainty in tive computed levels. The analysis shows that, of the sources of error considered, uncertainties in hydrophone calibration and source depths are dominant sources of error in the measured levels. Because of the large number of hydrophones used. they were not calibrated individually: instead an average calibration curve was used. The standard deviation of the calibration curve was about $2 \mathrm{~dB}$. The source depth used for each ship was an estimate of the depth of maximum cavitation on the propelier: the shaft depth minus $35 \%$ of the propaller diameter. The transmission loss varies as $20 \log y_{s}$, where $y_{s}$ is the source depth, so that the computed source levet is quite sensitive to errors in this estimate, especially for smaller ships or for tankers not fully ballasted.

\section{LINE STRUCTURE}

Appendix $C$ consists of a set of source-level spectra for all 14 ships processed for this report. The spectra are clearly dominated, up to about $60 \mathrm{~Hz}$. by a series of discrete lines. These are harmonics of the propeller shaft frequency $n$. If $B$ is the number of blades on a ship's propeller. the blade frequency $f_{1}=n B$. The blade frequency line and its harmonics are invariably higher in level ihan the rest of the shaft-rate harmonics. For the diesel ships, a firing-rate line. ypicaliy $f=9 n$, is comparable ii، level with the blade lines.

We compare our blade-iine results with the semi-empirica! model of Gray and Gresey [4;. This is a cavitation model which relates monopole line level, $L_{t}$. for the first few blade lir: 2 only iwo parameters. $f_{1}$. the blade fundamental frequency, and $V_{m}$. the maximum cavitation voiume on a propeller blade during a revolution:

$$
L_{i}=20 \log \left|\frac{\pi f_{i}^{2} \rho V_{-}}{2 \sqrt{2} r}\right|
$$

where $\rho$ is the density of the medium and $r$ is the reference range The maximu cavitation volume is estimated by the cmpirica: relation

$$
\nu_{\pi}=3\left(10^{-5}\right) D^{3}
$$

wher: the propeller diameter $D$ is in meters.

It is often desirable to characterize merchant ship ping as distributed in two fundamental parame1ars: ship length and speed. empirical formulas to relate blide frequency and propeller diameter to ship length in meters in the Gray-freeley model are:

$$
f_{1}=8 H z . D=0.12 L^{3 / 2} \text {. }
$$

where the propeller diameis $D$ and ship length $L$ are in meters. In comparing the NRL measurements with the Gray-Greeley model !4l. we can use the actual known propeller parameters. Figures i0. 11. and 12 are plois relating measured and predicted levels for the first three blade lines for all 14 ships. The mean and standard deviation of the difference is shown for each graph. These measured-predicted differences are very large for the blade fundamental, and decrease markedly as the harmonic number 


$$
E
$$


WRIGHT :ND CYBULSKI

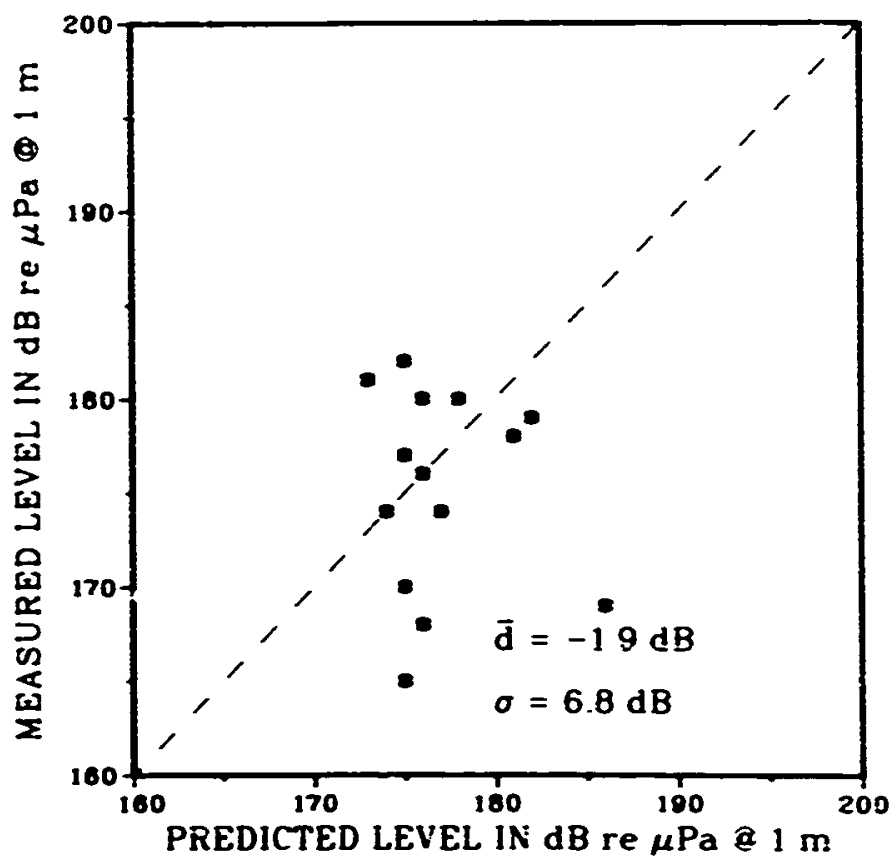

Fis. 12 - Measured source levels is modal predxtions for second blade harmionics of lis ships

increases. while the standard deviation is about $6 \mathrm{~dB}$ for each comparison. This standard deviation is about the same as that antributed in Ref. 3 to the empirical formula above, relating maximum casitation volume io propeller diameter.

The model predicts that the first three biade lines of a given ship will have equal source level. It is evident that our measurements disagrec markedly for frequencies below about $15 \mathrm{~Hz}$, or approximately for the first two blade lines. For the third biade line. the differences between measurement and model are within the variances estimated by Gray and Greeley. about $8 \mathrm{~dB}[4]$. The measured ievels suggest sirongly that the caritation model is inadequate for lerge ships. below about $15 \mathrm{~Hz}$.

A useful way of presenting source-level data is in the form of a frobability distribution of source iesels. Gray and Greeley applied their semiempirical model to an estimated distribution of ship parameters in the world merchant fleet, and produced estimated source-ievel distributions as functions of ship size class and source depth. The appropriate comparison for the NRL data sample is their estimated distribution for all world merchant ships over $700 \mathrm{ft}$ in length, with source depth taken as $32 \mathrm{f}$. Figure 13 shous the distribution of the NRL data (12 ships over $700 \mathrm{ft}$ in length) plotted as solid bars. with the Cis ay-Gieeley distribution plotled as dasied bars. The NRI data set is for the second blade harmonic: i.e. for the frequencies above about $15 \mathrm{~Hz}$. Our sample peaks at abour the same level as the motel distritution, but has less variance about the peak.

The discrete lines in a ship spectrum are of a complex nature. Figure 14 is a plot of a time-series of recered-level spectra in a 1-Hz interval about the blade fundamental of the Worid Dignity. al large steam-powered tanker. Time increases down the page an 8-5 intervals. An arbitrary floor level simplifies the plot except in the high-intensity time window near CP. The frequency of the blade t.armonic oscillates in sautoryth fashion about its me n value of $7.2 \mathrm{~Hz}$, with a period of abotit $2 \mathrm{~min}$. The amplitude of this oscillation, about $0.1 \mathrm{~Hz}$. is la.ee enough to obscuse the doppler-shif inee on the 
NRL REPORT 8677

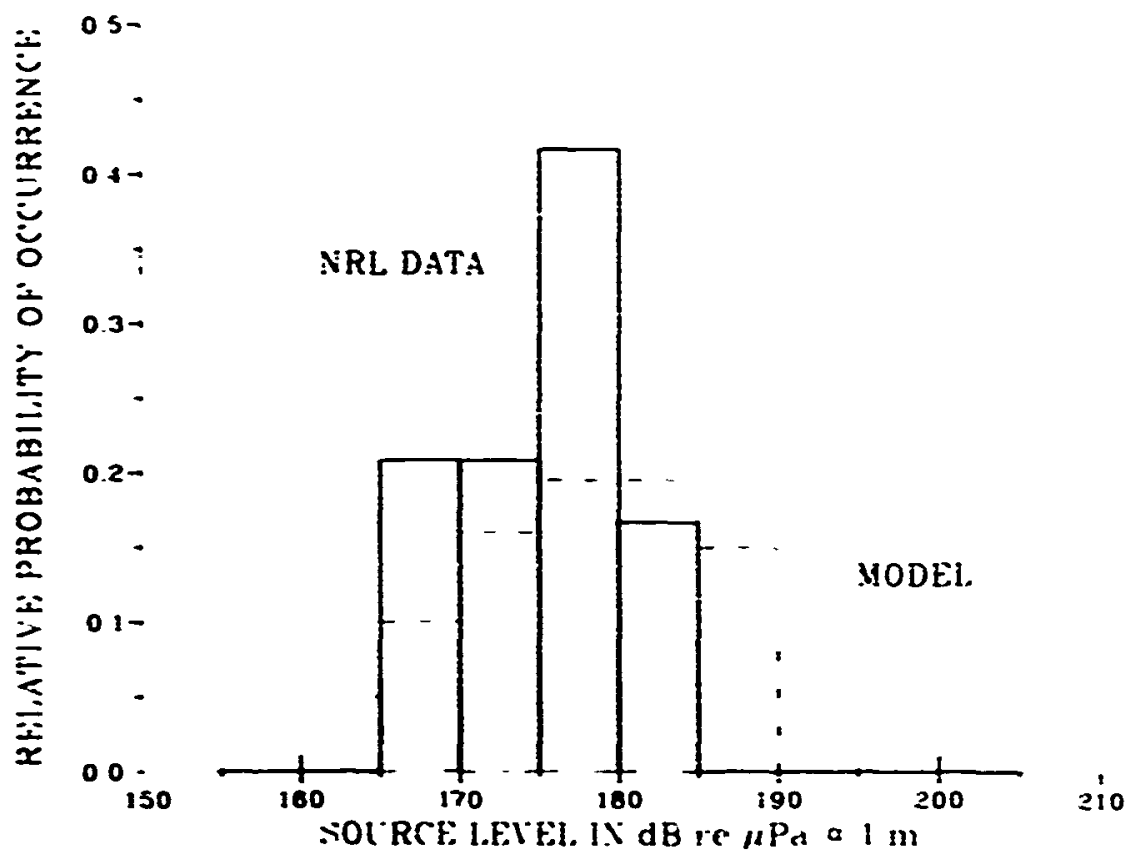

Frs. 13 - Frequency dsirbutwon of measured second bladt hamona soures is:els for 12 latge ships. with predeted distribution for woild merchent flesi

curse. The other blade lines of this ship show the identical oscillation. with amplitude proportional to line frequency, indicating that the propeller shaft rate varies about $\pm 1.0 \%$ about its mean value. presumably because of long-term shaft depth or wake variations for a ship under way. Ifosi ships showed this kind of long-term line frequency variation, with the median amplitude 0.3 of mean line frequency.

In addition io a long-term frequercy variation, the discrete lines in the ship spectia have complicated structures, which apfear to include sidebands. It is not possible to characterize the spectral lines adequately by simpie 3-dB bandwidths: we have selected the weighted rooi-mean-square banduidith as the meinod of computing line width. This is defined, as by Shooter et al., [S] by the equation:

$$
B W=\frac{\sum_{i=1}^{N}\left(C_{i}-N\right) \cdot\left(f_{i}-\bar{f}\right)^{2}}{\sum_{i=1}^{x_{N}}\left(C_{i}-N\right)} \text {, where }
$$

$f_{3}$ is the frequency corresponding to the th Fourier amplitude $C$, of the frequency spectrum. $N$ is a noise floor estimate for the Fourier amplitudes in :he st:mmation window from $i=1$ 10 $\hat{1}_{\ldots}$. and $\bar{f}$ is a weighted mean frequency:

$$
\bar{f}=\frac{\sum_{s=1}^{s}\left(C_{s}-N\right) f_{i}}{\sum_{i=1}^{i}\left(C_{-}-x\right)}
$$


An analytical model for broadband source level in the continuous spectrum is that of Ross [1]. which relates monopole source level, $L_{B b}$, to propeller tip speed, $U_{t}$, and number of blades. $B$. by the formula

$$
L_{b s}=L_{0}(f)+60 \log \frac{U_{t}}{25 \mathrm{~m} / \mathrm{s}}+\mathrm{i} 0 \log \frac{B}{4} .
$$

where $L_{0}(f)$ is an empirical function of frequency. In Figs. 16 and 17 . measured broadband levels are plotted against levels predicted by the Ross model for two frequencies, 50 and $100 \mathrm{~Hz}$. the mean difference and standard deviations for these curves are comparable with those for the discrete-line comparisons.

Theoretically modeled hioadband source levels invariably decrease monotonically on either side of a peak frequency generalls between 50 and $100 \mathrm{~Hz}$. The measured source level spectro tend to have peaks in this frequency ange, but they also show a sharp rise with frequency decreasing helow about 15 Hz. One possible cause which was considered for these large low-frequency values was induced flow noise in the turbuient boundary laver on the ship's hull [7]. To test whether this dipole radiation might have been det:cted in our shont-range measurements, the flow-noise-induced levels were computed as functions of time for extended sources simulating all 14 ship hulls passing the sonobuors. The computed rcceived-level spectra agree well in frequency dependence with the measured levels. down to abou: $4 \mathrm{~Hz}$. but they are $10 \mathrm{~dB}$ or more lower than the measured levels. Also, the measured shafi- and blade-line levels appear to increase with decreasing frequency in the same fashion. A tentative intpothesis is that the lines excite hull vibrations which reradiate energy detectable at short range, and that the broadband energy: detected consists of pedestals and sidebands of the lines.

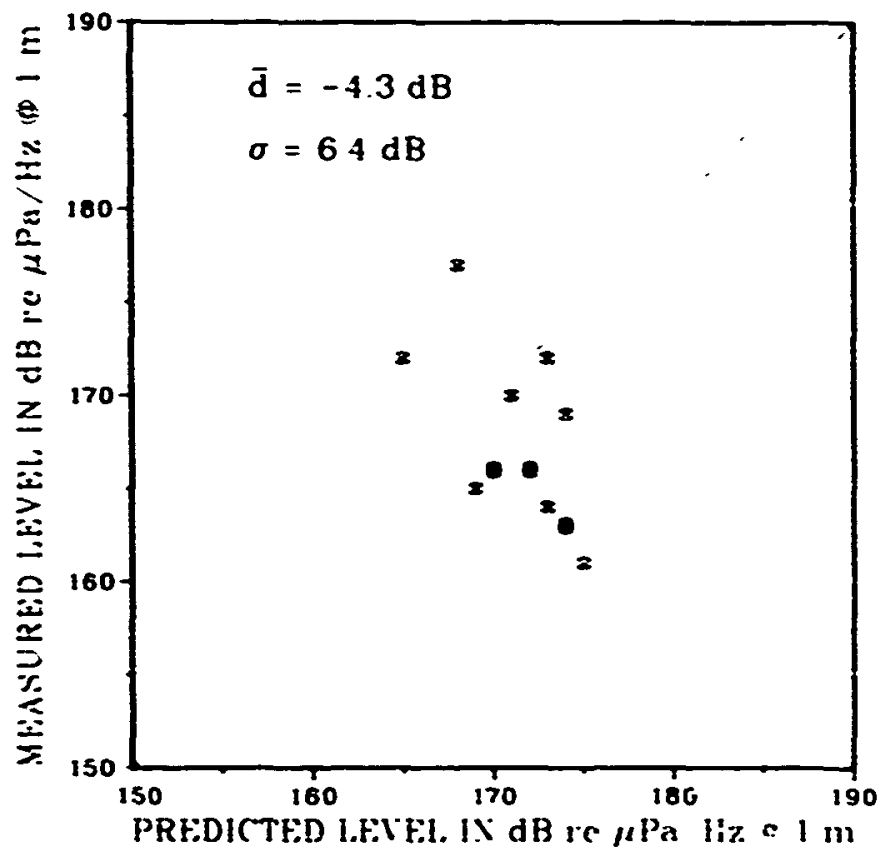

Fo it - Measured source kevek is model precixtonas for the frequence contunum at it llz. for li shro 
NRL REPORT SOT:

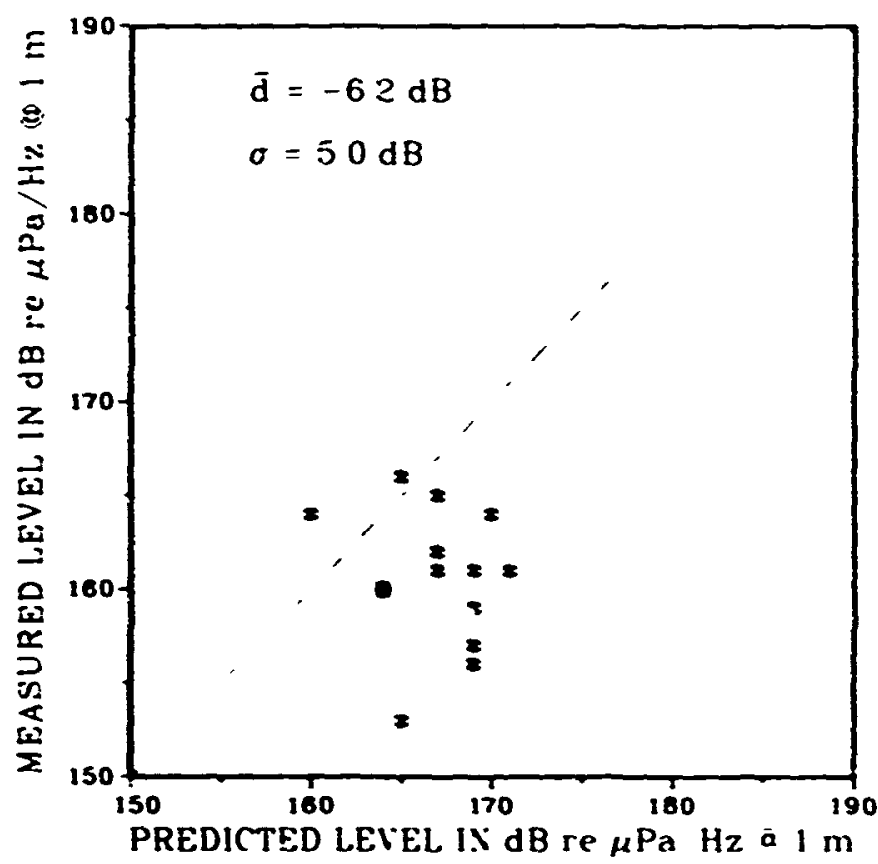

Fa. 17 - Measured source levels is model predicions for the frequency contisum at 100112 for it ships

\section{CONCLUSIONS AND RECOMMENDATIONS}

In the NRL experiments, air-dropped sonobuoys weie used successfully for source-level measurements of 14 ships. With our receiver depth of $305 \mathrm{~m}$. measurements in the frequency range of 15 to $128 \mathrm{~Hz}$ can be made with two buoys at about 300 to $600 \mathrm{~m}$ and 800 to 1206 in from the ship's track. The method of dropping an equally spaced line of five buoys produced this result in almos: all cases The error analysis indicates that our measured source levels are valid to within $\pm 6 \mathrm{~dB}$ in the frequency range 15 to $128 \mathrm{~Hz}$.

The observed increase in blade-line level with decreasing frequency, below about $15 \mathrm{~Hz}$, is not predicted by a recently formulated shipping noise model $[4]$. Above this frequency. our measured monopole blade-line levels are comparable with model predictions. withir. an estimated variance about equal to that predicted by the model. The rising levels at the lowest frequencies may be caused by reradiation from the ship's hull: this question should be investigated further. Root-mean-square blade-line bandwidths are approximately proportional to blade-line number, and this is iikewise consistent with current mode! predictions.

Our measured broadband levels at two selected frequencies are about $6 \mathrm{~dB}$ below ine monopole levels predicted by the Ross model. with variance also abou $6 \mathrm{~dB}$.

It is recommended that further studies be inneycied of biate-line width and tine structure. The NRL shipping roise data base is a uniquely appropitime and cenvenient resource for such studies.

\section{ACKNOWLEDGMENTS}

Thanks to Dr. Orest Diachok. Dr. Budd B. Adanis, and Dr. Ron Dicus for many heipful discussions, and to David Dichl for helping with the messurements and dita processing. 


\section{REFERENCES}

1. D. Ross. Mechanics of Underwater Noise. Pergamon Press (1976).

2. J. Cybulski, "Probable Origin of Measured Supertanker Radiated Noise Spectra-" Oceans 77 Conference Record. 1. Institute of Electrical and Electronic Engineers, 15C/1-8.1977.

3. H.W. Kutschale. "Rapid Computation of Wave Theory of Propagation Loss in the Arctic Ocean." Lamont-Doherty Geological Observations of Columbia Univ. Tech. Report No. 8. 1973.

4. L. Gra;, and D. Greeley: "Source Level Model for Propeller Blade Rate Radiation for the World's Merchant Fleet." Technical Memorandum 458. Bolt. Beranek and Neuman. Inc.. Cambridge. Mass. 02138. 1978.

5. J.A. Shooter et al.. "Characteristics of Ambient Noise in the Deep NW Pacific." ARL-TR-79-39. Applied Research Laboratories. POB 8029. Austin. Tex. 78712.

6. W.D. Mark. "Effects of Rotational Speed Fluctuations and Inflow. Turbulence on Merchant Ship Propeller Cavitation Volume Spectra." Technical Memorandim \#660. Bolr. Beranek and Neuman. Inc.. Jan. 1982.

7. Wright, E.B.: "Flow-Induced Noise in Merchant Ship Broadband Source Levels." J. Acoust. Soc. Am. 65(S1). S89(A). 


\section{Appendix A \\ OPERATIONAL CONDUCT OF EXPERIMENTS}

\section{Sensor Hydrophone and Environmental Constraints}

Acoustic instrumentation uas arailabie in the form of AN/SSQ-57A $(X N-5)$ sonobuoy, modified [Al] for very low frequency (VLF) response to $1 \mathrm{~Hz}$ with a $305 \mathrm{~m}$ hydrophone. This unit is air deployable from the NRL EP3A research aircraft. A deep njurophone sensor was selected to receive signals uncontaminated by a bottom return for range separations as great as possible, to acivire reliable data approaching bow and stern ship aspect angles. However, the modification of the buoys was such that they were considered to be self-noise limiting at about sea state 3 . generally characterized by whitecaps of $1.5 \mathrm{~m}$ wave height.

Thus. an important consideration was the daily Fleet Weather Center (FWC) forecast of wave height contours over the areas of interest. Personnel of FWC ROTA. Spain provided a real wave height 2 to $\mathrm{S} \mathrm{ft}$ contours in $1 \mathrm{ft}$ intervals. With this chart daily operations were logically restricted to those regions of a 3-ft wave height and less. Generally the prognostications were found to be accurate. although generally higher by about $1 \mathrm{ft}$.

\section{Aircraft Platform-Typical Operations}

Staging out of ROTA permits the aircraft to reach the farthest operating area selected with 2 hours Iransit. This allows 6 hours to search for ships. ships' screening and acceptance. rigging (snips' course. speed and photographs) and acoustic data acquisition procedures before a transit back to base while maintaining flexibility as to alternate landing fieids. The Litton Inertiai Navigation System (INS) aboard an aircraft was to be the primar: navigational instrument. During the transit to the shipping lane in the area. a ealibration is made of the analog and digital systems employing $C W$ tones and a random noise geacrator with a transmitter test set. After reaching the shipping lane. a search either to the north or south is made. After an acceptable vessel is found it is rigged and at least four mark-on-tops (ASOT) a: : atien over a $30 \mathrm{~min}$ period to establish course and speed. A check has been made for prorimity of other ships so try to maintain a separation of 10 to $15 \mathrm{nmi}$ at the estimated CPA to sensor deployment. During this period a photograph abeam and astern is taken and an aircraft expendable bathythermograph (AXBT) drop is made. The navigator dead-reckons an INS position approximaiely $45 \mathrm{~min}$ ahead of the ship. and the sonobuoy deployment an begins from a point $10 \mathrm{nmi}$ perpendicular to the track at an altitude of $91 \mathrm{~m}$ and a speed of 180 knots. Five buoys are dropped at $10-5$ intervals ( $0.5 \mathrm{nmi}$ sfacing) with the initial buoy scheduled $1 \mathrm{nmi}$ of? the ship s course. After deployment, additional MOTs are taken and several passes made over the buoy line using the on-top-position-indicator (OTPI) to mainiain a DRT plotter.

\section{Instrumentation}

The aircraft contains all of the instrumentation fer reception, monitoring. analog recording and calibration. The outbut of the conventional sonobuoy receivers $(A R R-52)$ down to $2 H z$ was obtained by lising the discriminator output jack. Speciral essimates in the 0 to 20-Hz and 0 to $500-1 / 2$ bands were made on-line by using a (UA $\mathbf{5 0 0}$ ) specirum analyzer. A broadband 10 to $\mathbf{4 0 0} \mathbf{H z}$ ) sirip chart recorder provided aditional monitoring of tape-recorded signais including $a$ time code and a referense frequency. The primary processing was done on-line where ine received signals from five sensors were sampled. held and multiplexed for simultaneous $A-D$ conversion of the input into a Fourier analyzer. 
This system [A2] was under control of a (HP21005) computer which also accepted the INS data. The thermal structure to $305 \mathrm{~m}$ was available from AXBT chart records made during each deployment.

\section{REFERENCES}

A1. Ricalzone, L.C. and J.R. McGrath: "Modification of the AN/SSQ-57A (XN-5) Sonobuoy for VLF Applications," J. Acoust. Soc. Am. 60, 1414-1416 (1976).

A2. Steiger, D. and J.D. Clamons: -NRL's Oceanographic Computer System: Present Capability and Future Enhancements,- NRL. Memorandum Report 3216, 1976. 


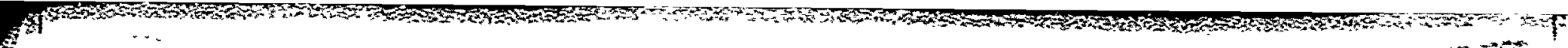




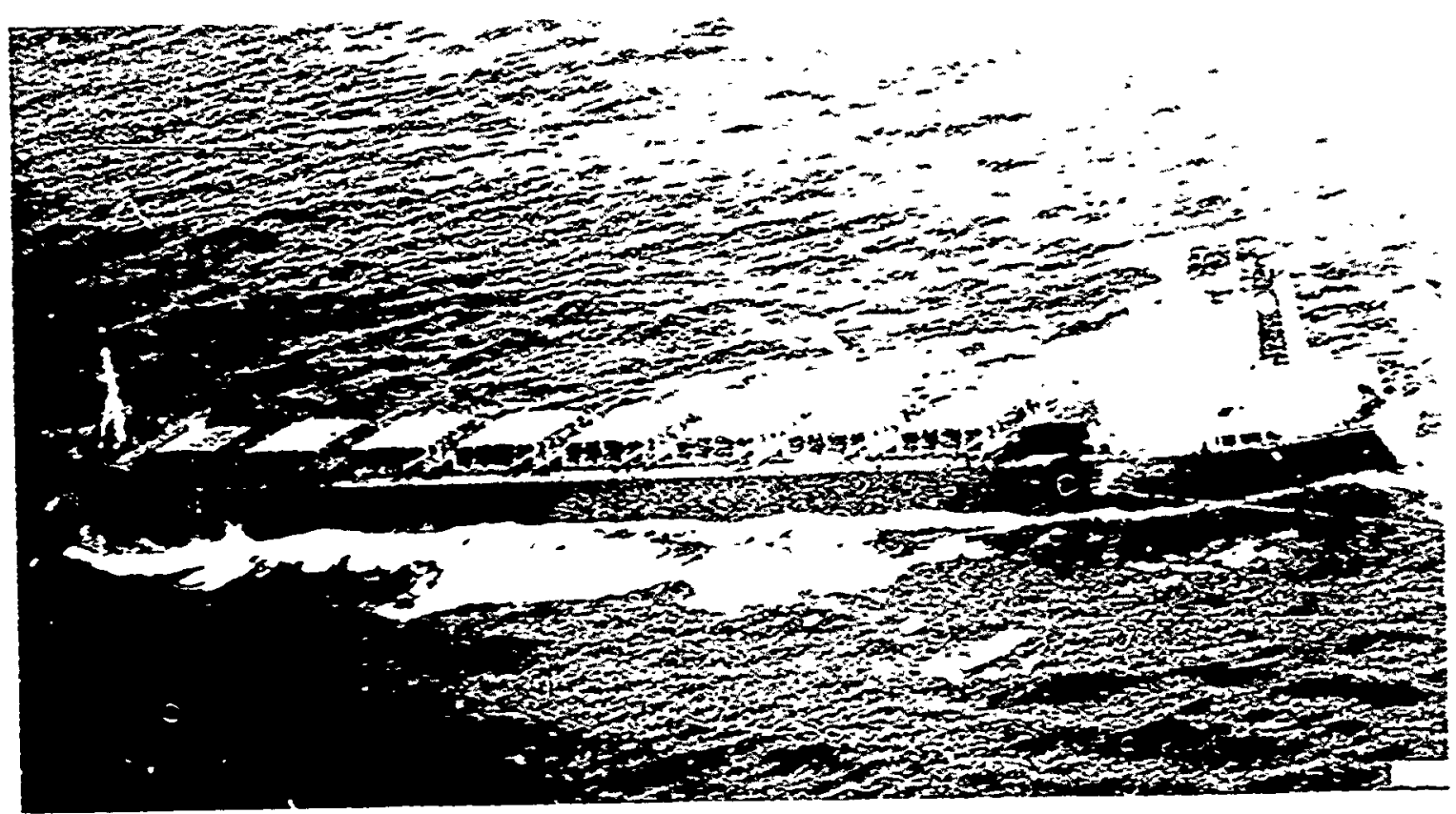

f: BI- Beicargo

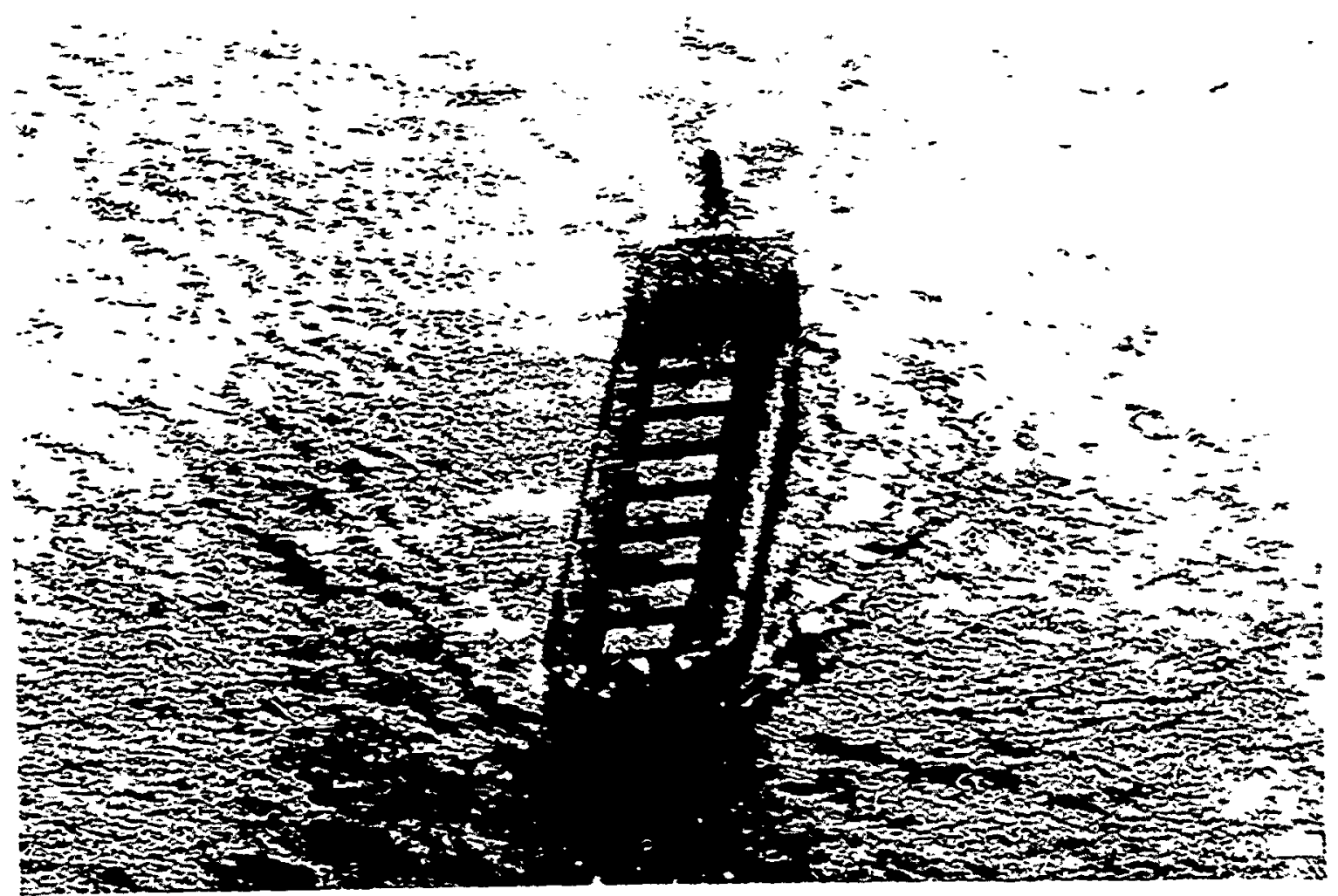

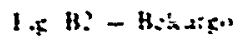




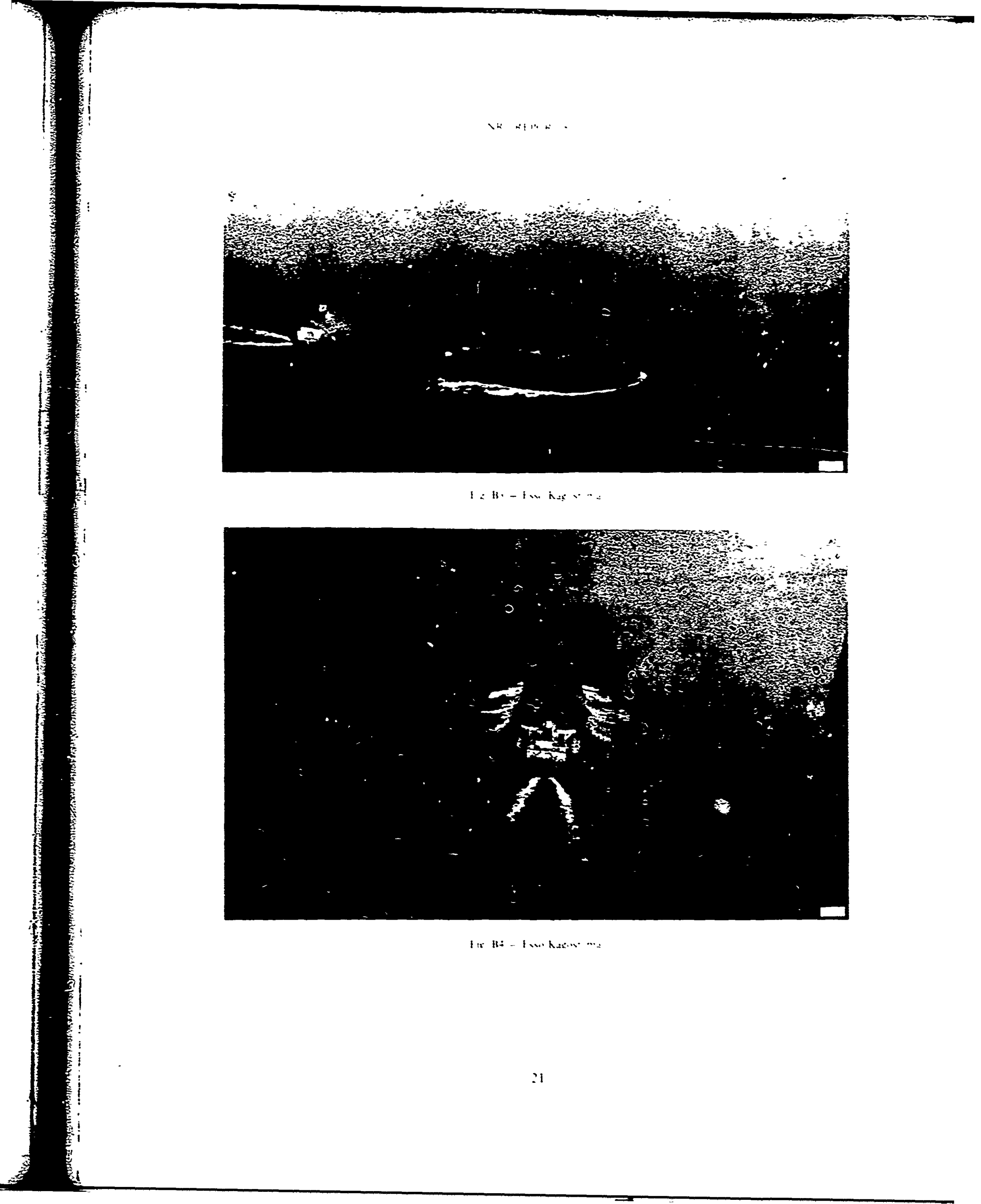




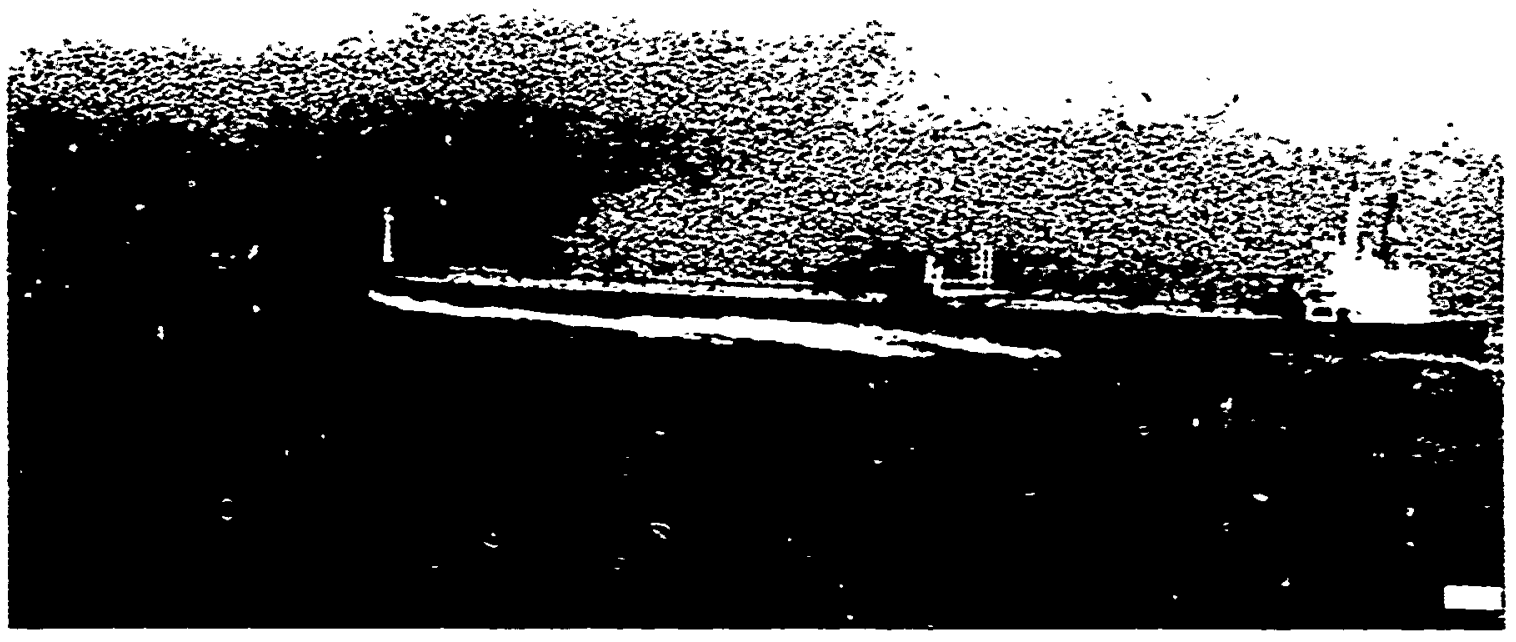

I B Bi -1 Trons

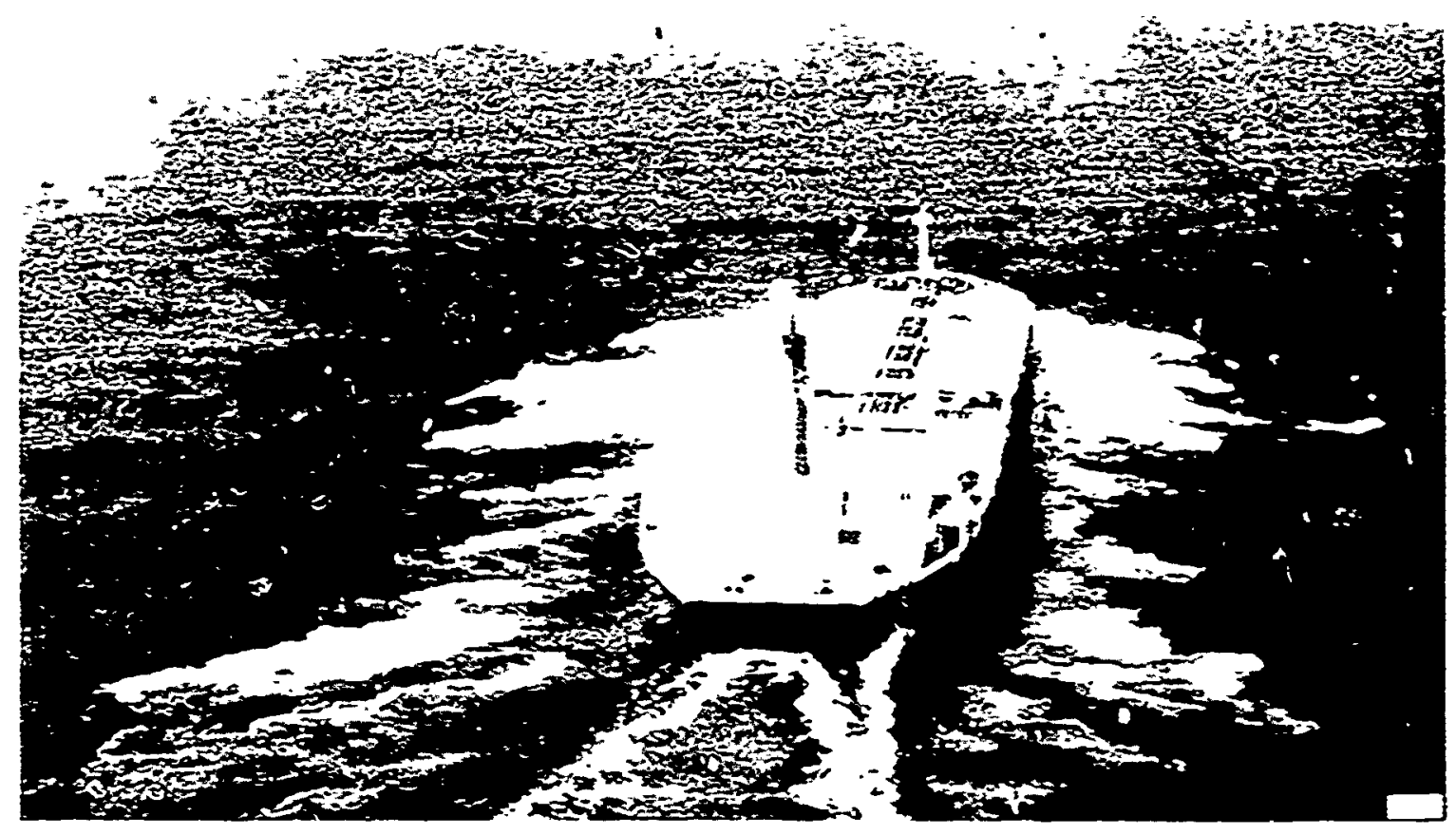

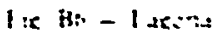


VHL. REP(IRT X67

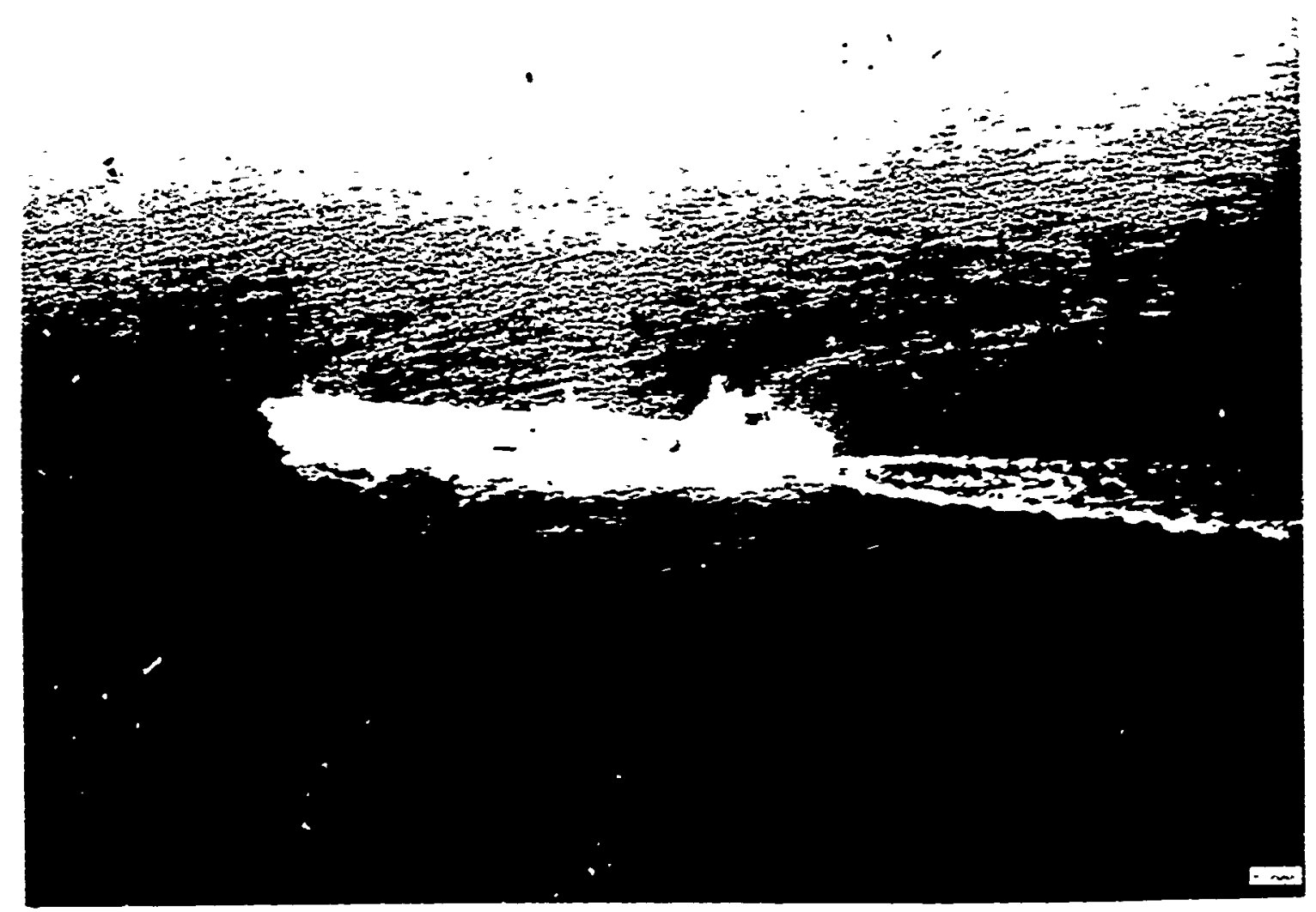

Fis $\mathrm{B}^{-}-$Iostoks

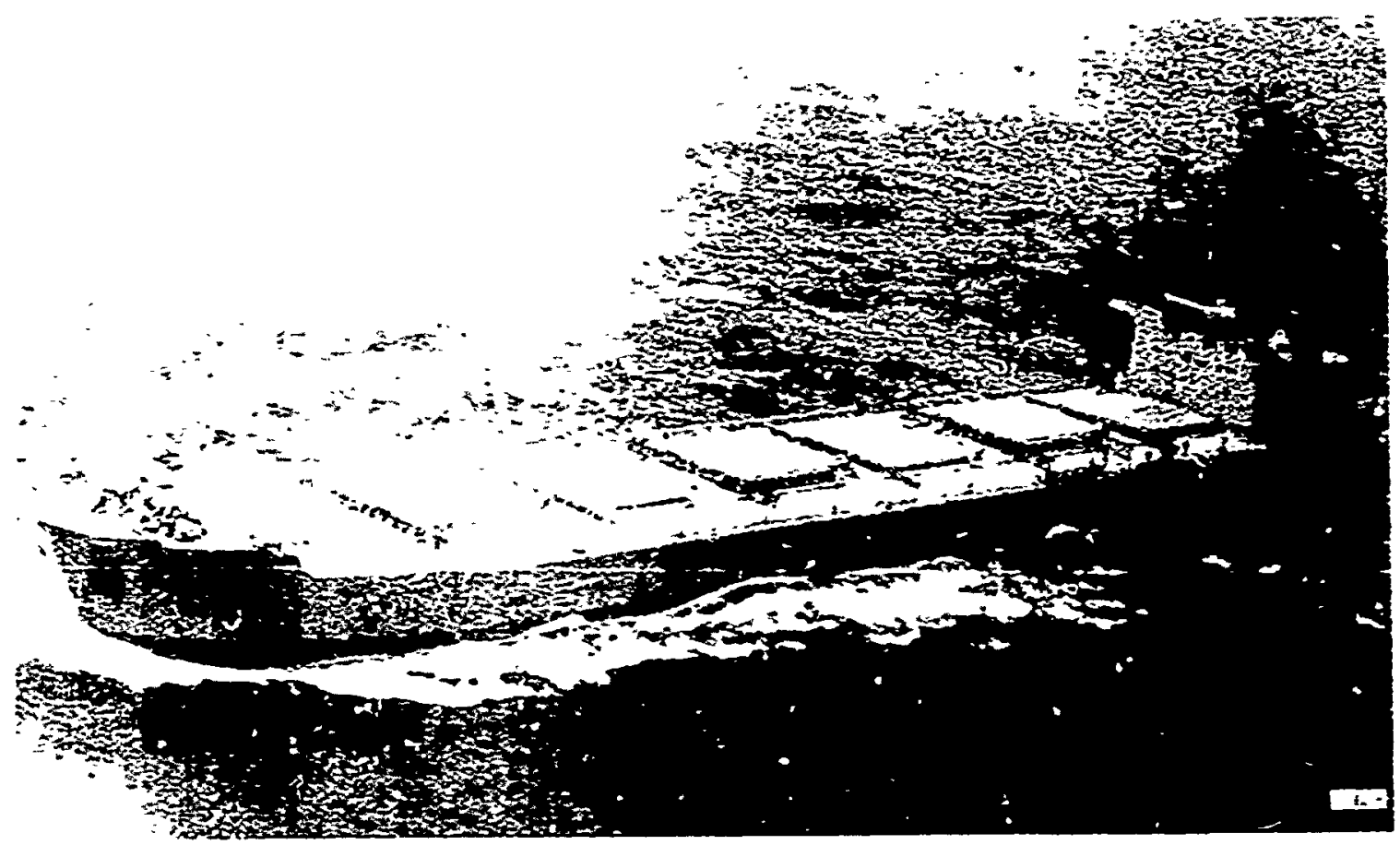

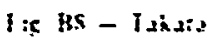


VRI R!P()R I Ye $=$

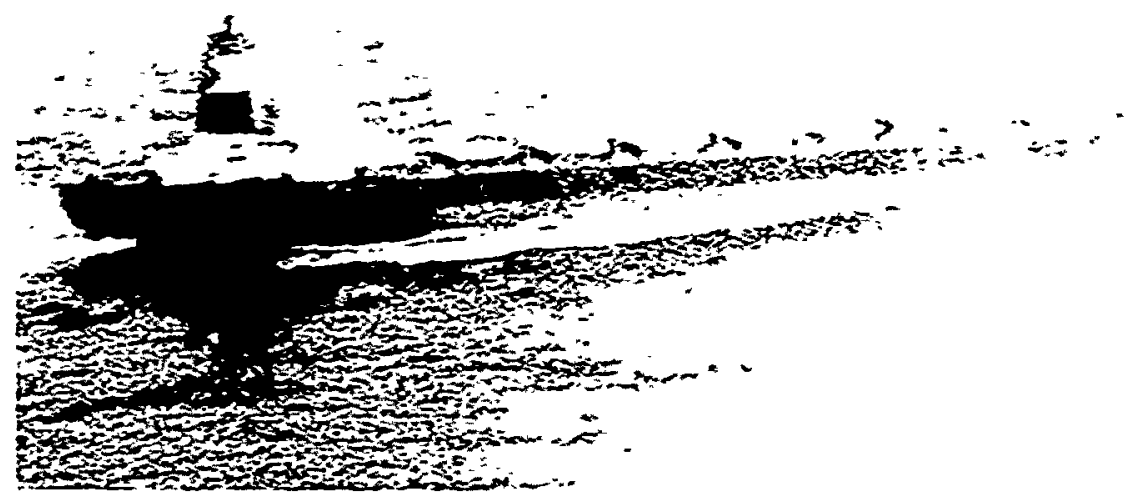

Fas BH - Tho:

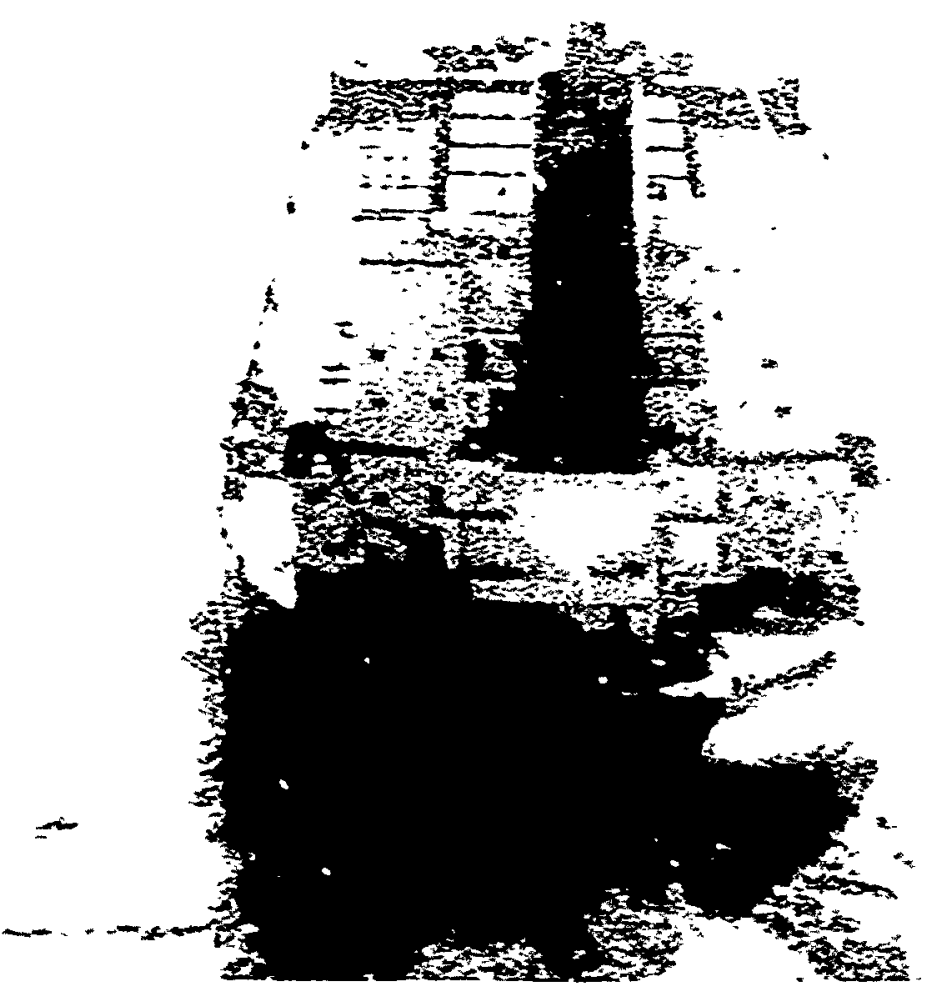

$5 \times 8 ! !-1 \div$ 

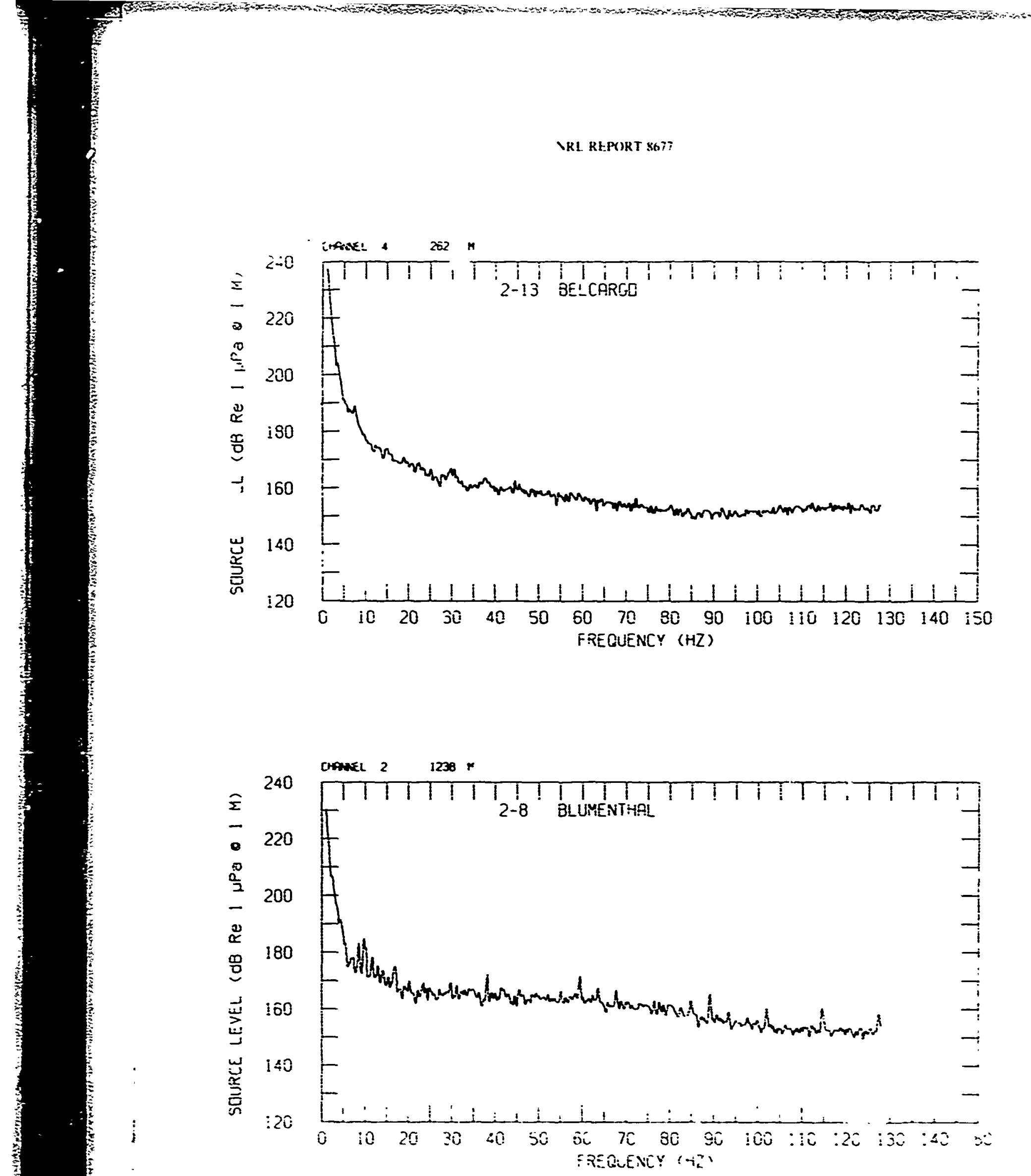


\section{Appendix C \\ MEASURED SOURCE-LEVEL SPECTRA}

This sei of source-level curres includes all usable measured spectra with CPA ranges in the 2001300-in. window mentioned in the texi. The CPA range appears abote each plot. The hyphenated number preceding each ship name is the phase/run number. 


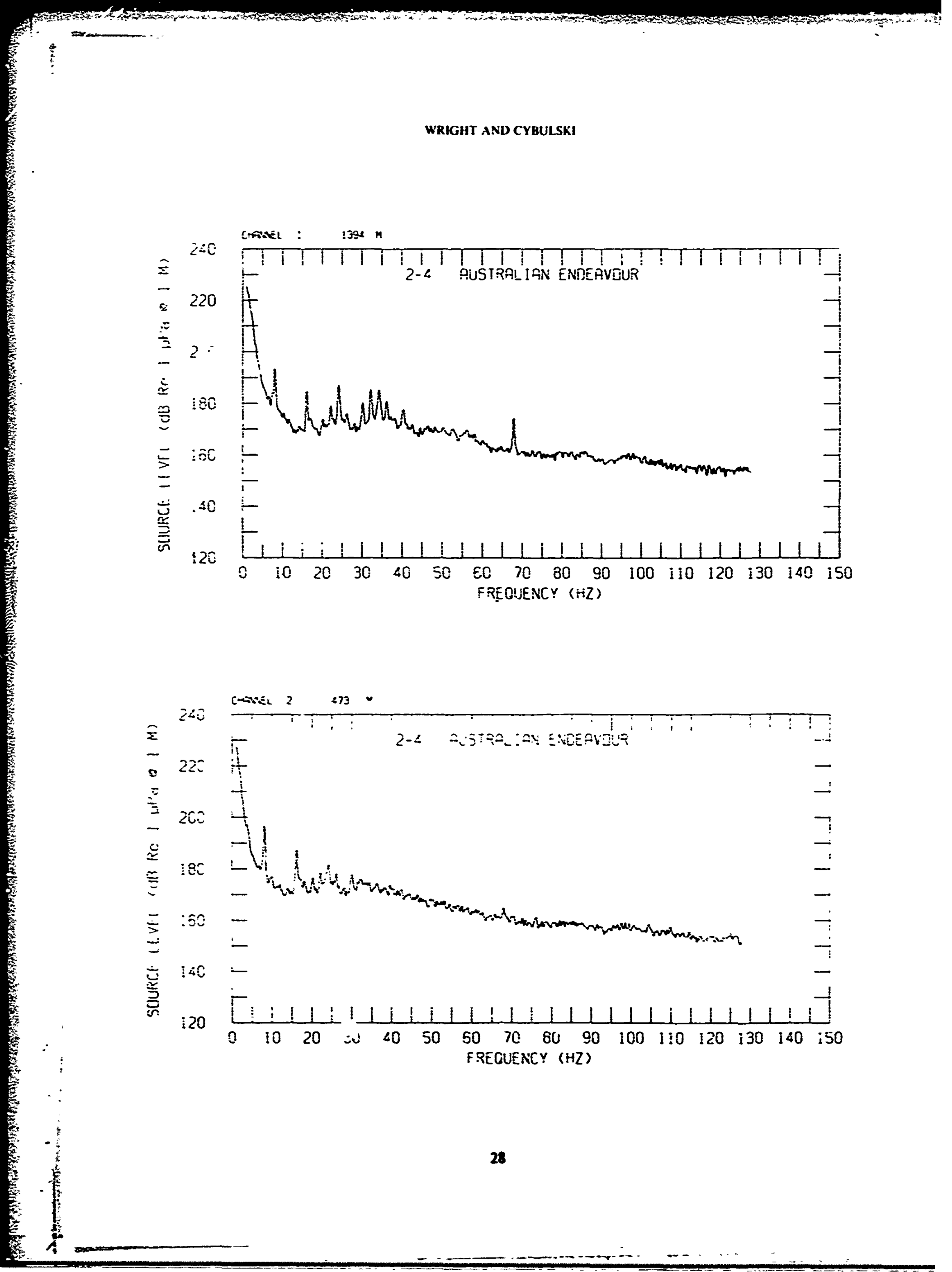


NRL REPORT $\$ 677$
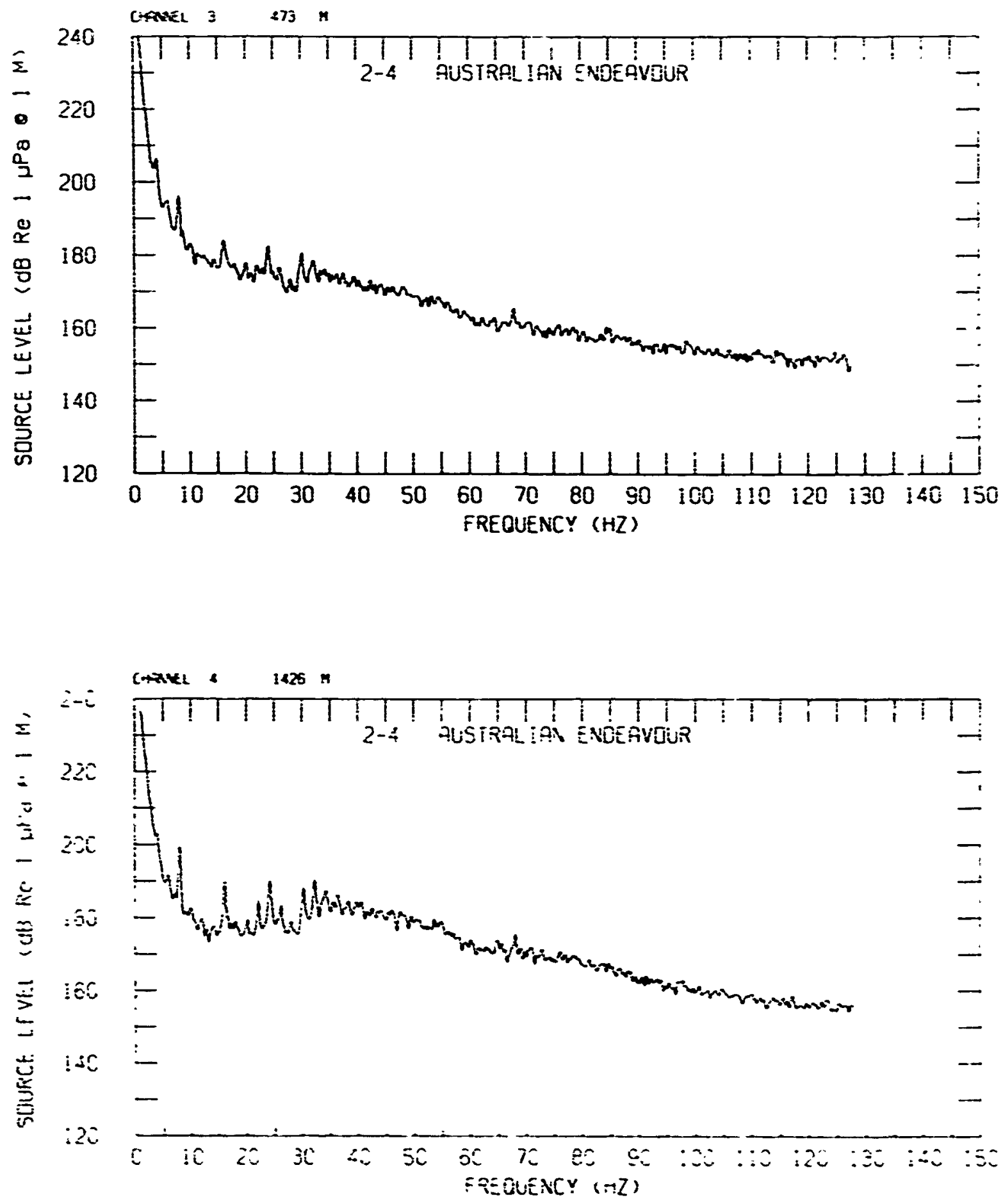

29 
WRIGHT AND CYBULSKI
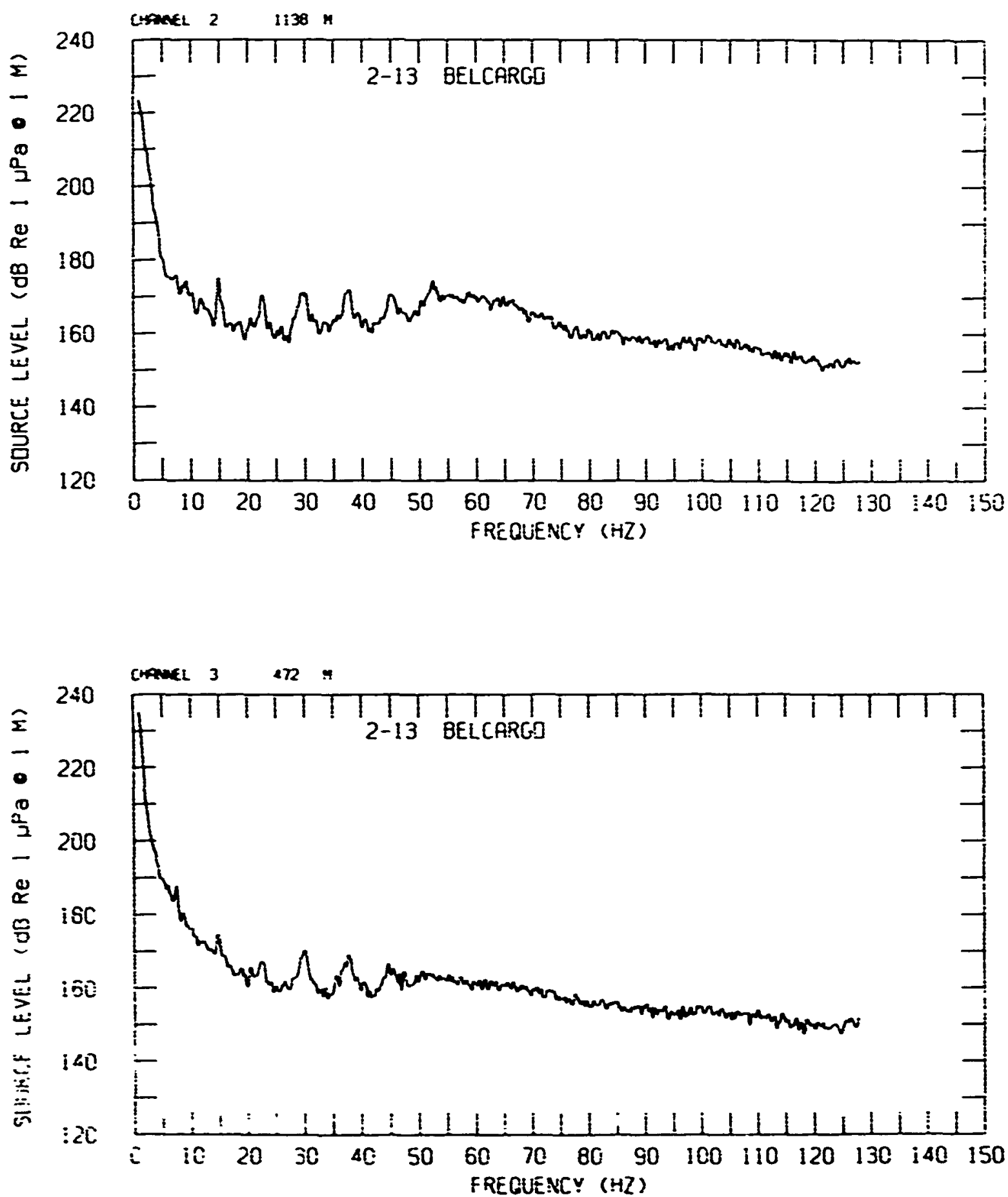

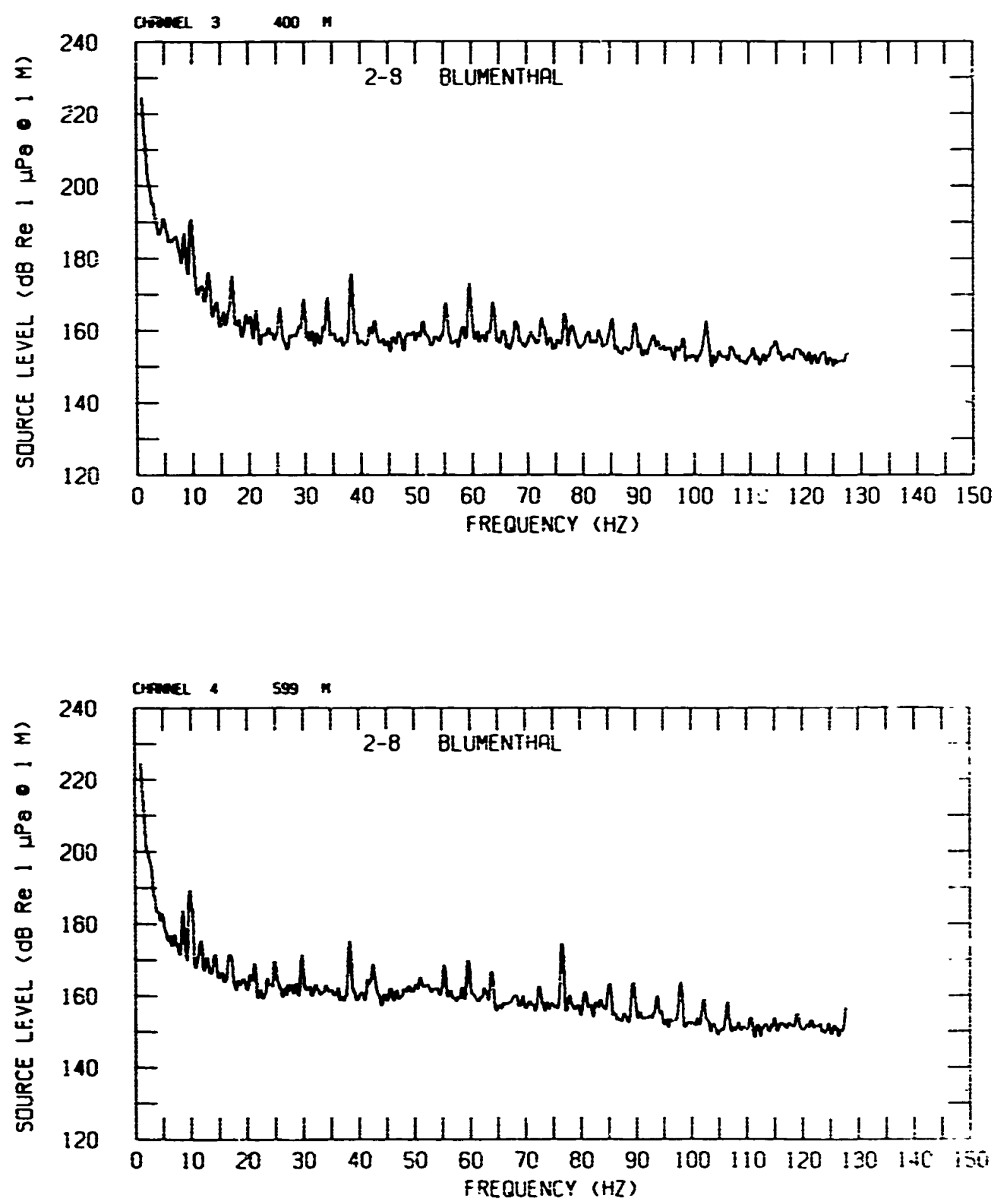

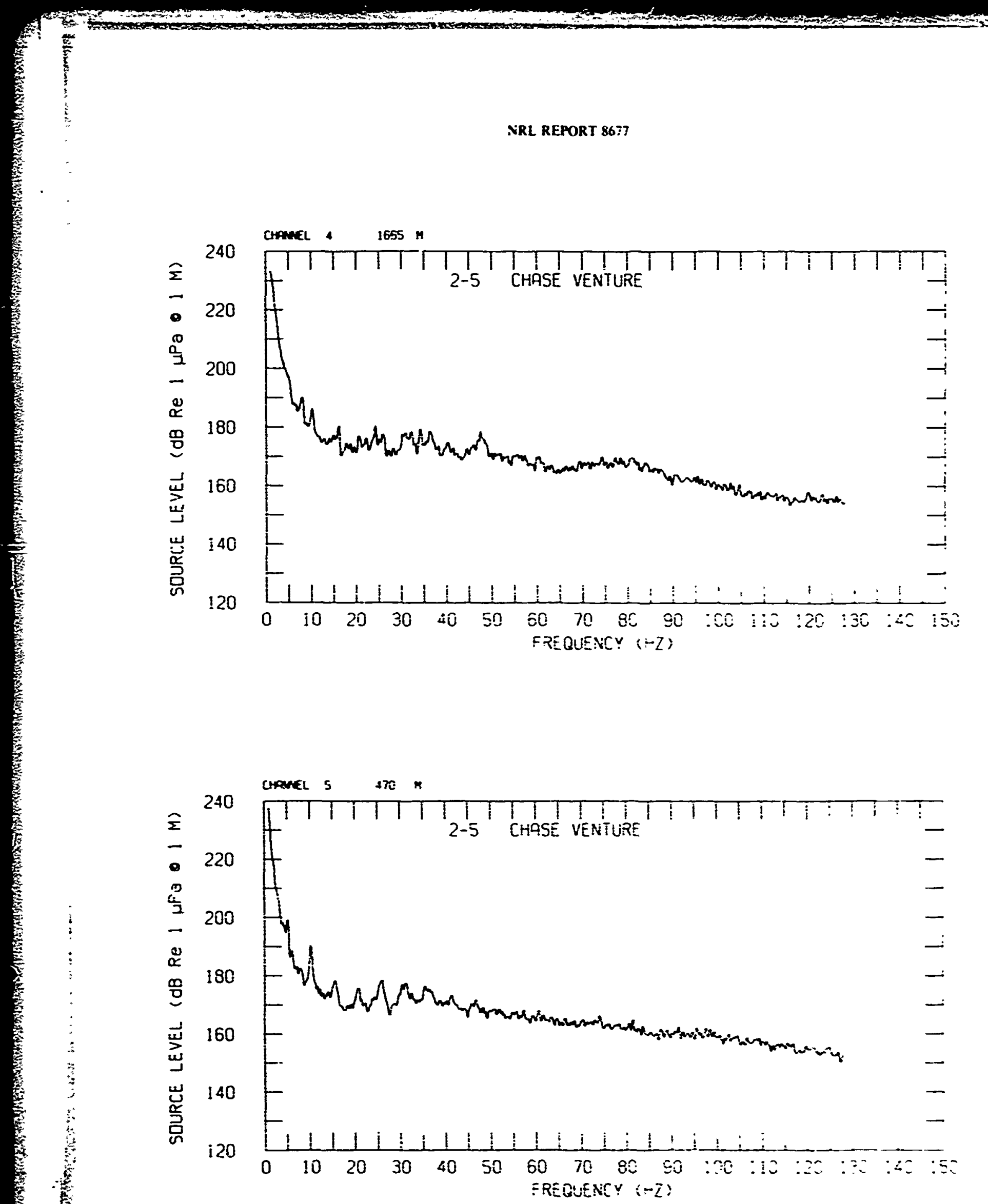


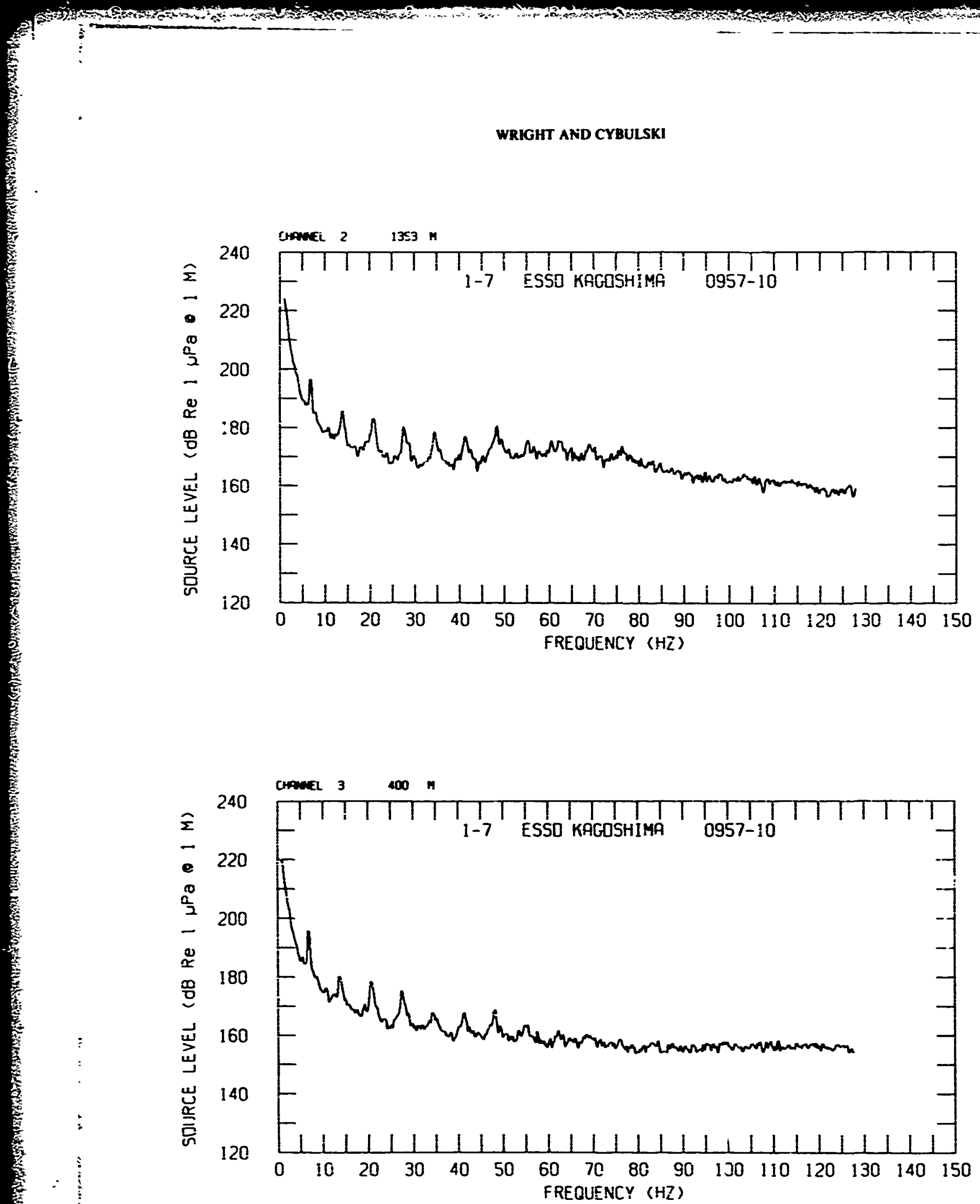


NRL REPORT 8677
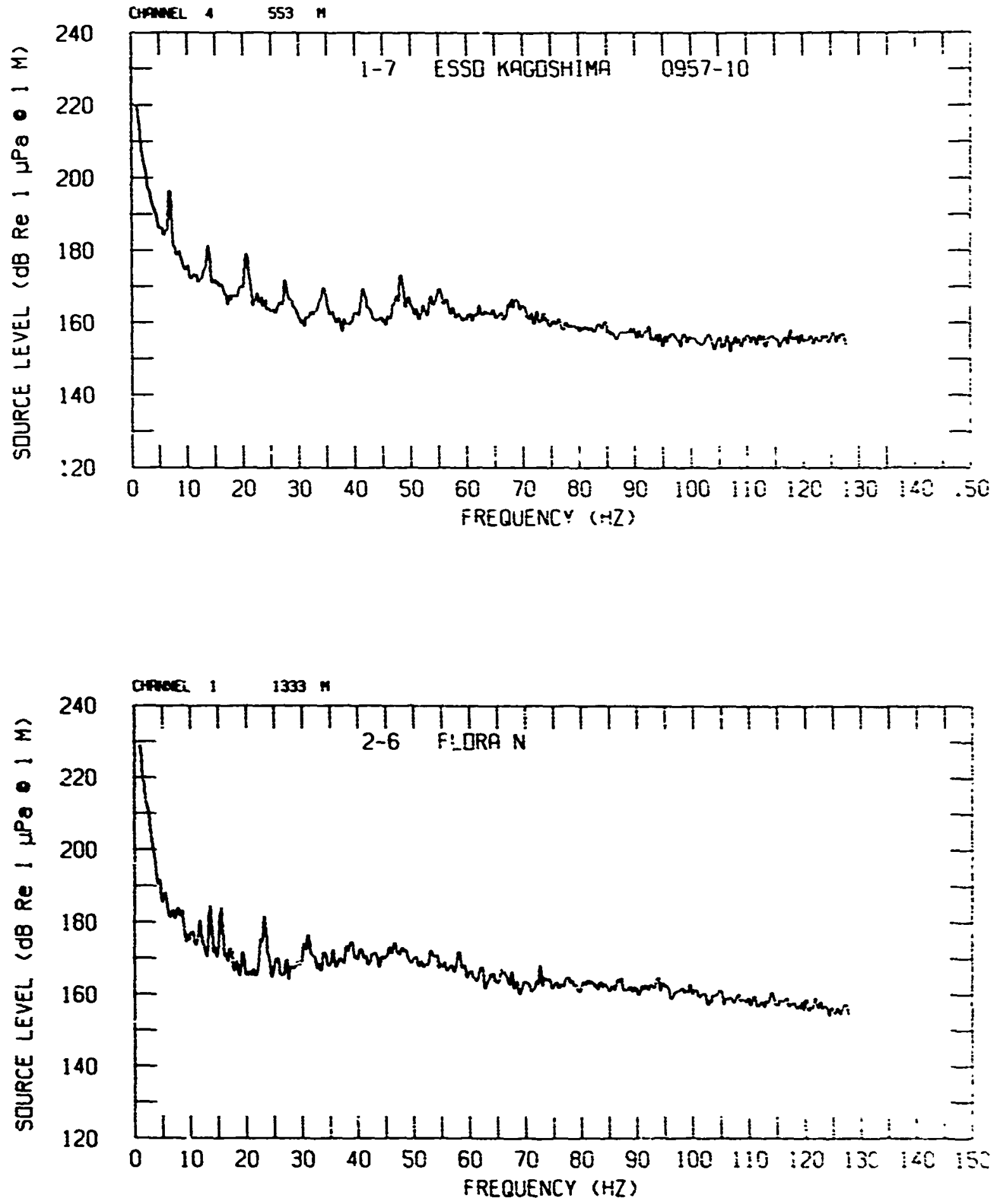
WRIGHT AND CYBULSKI
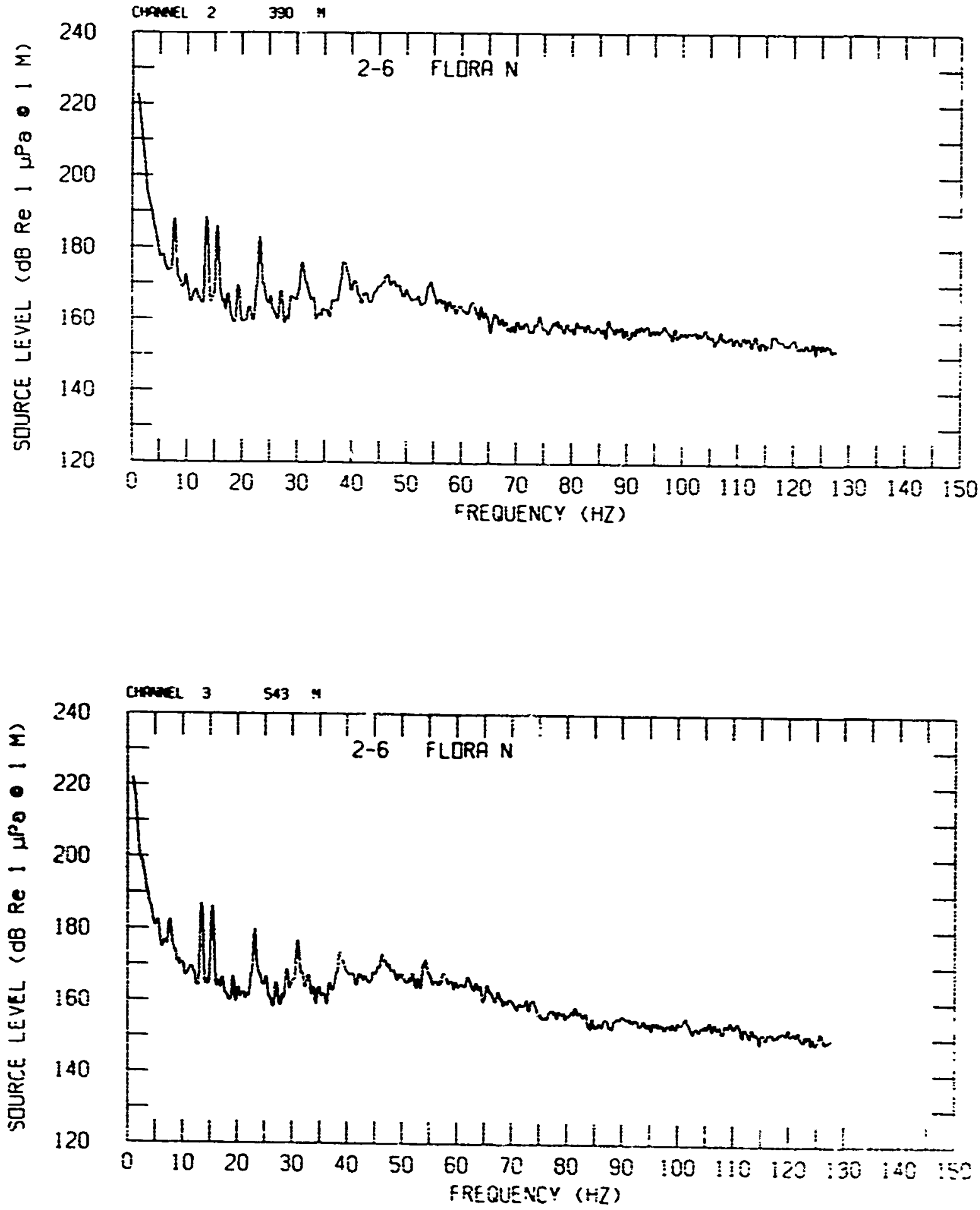
NRL REPORT 8677
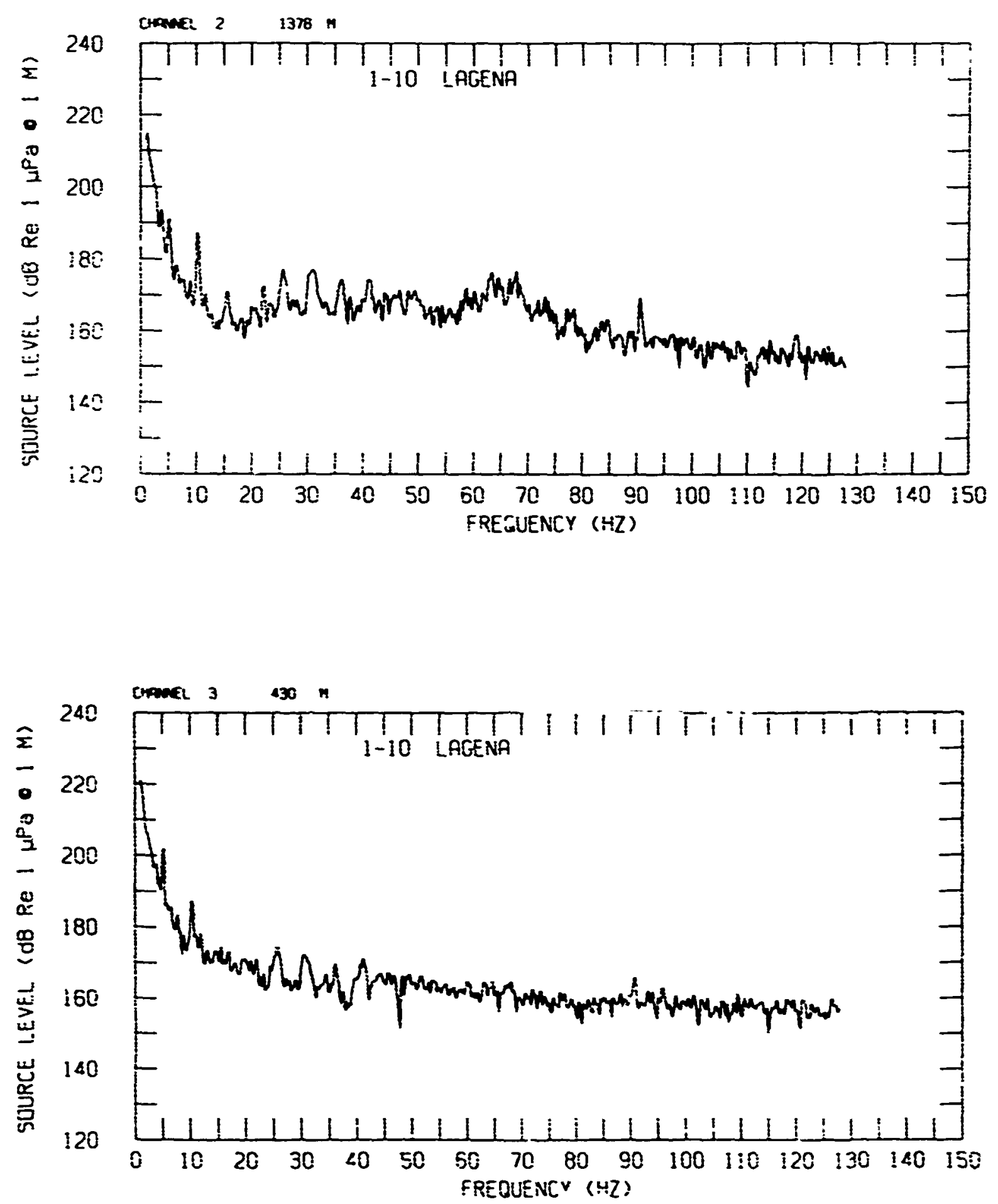


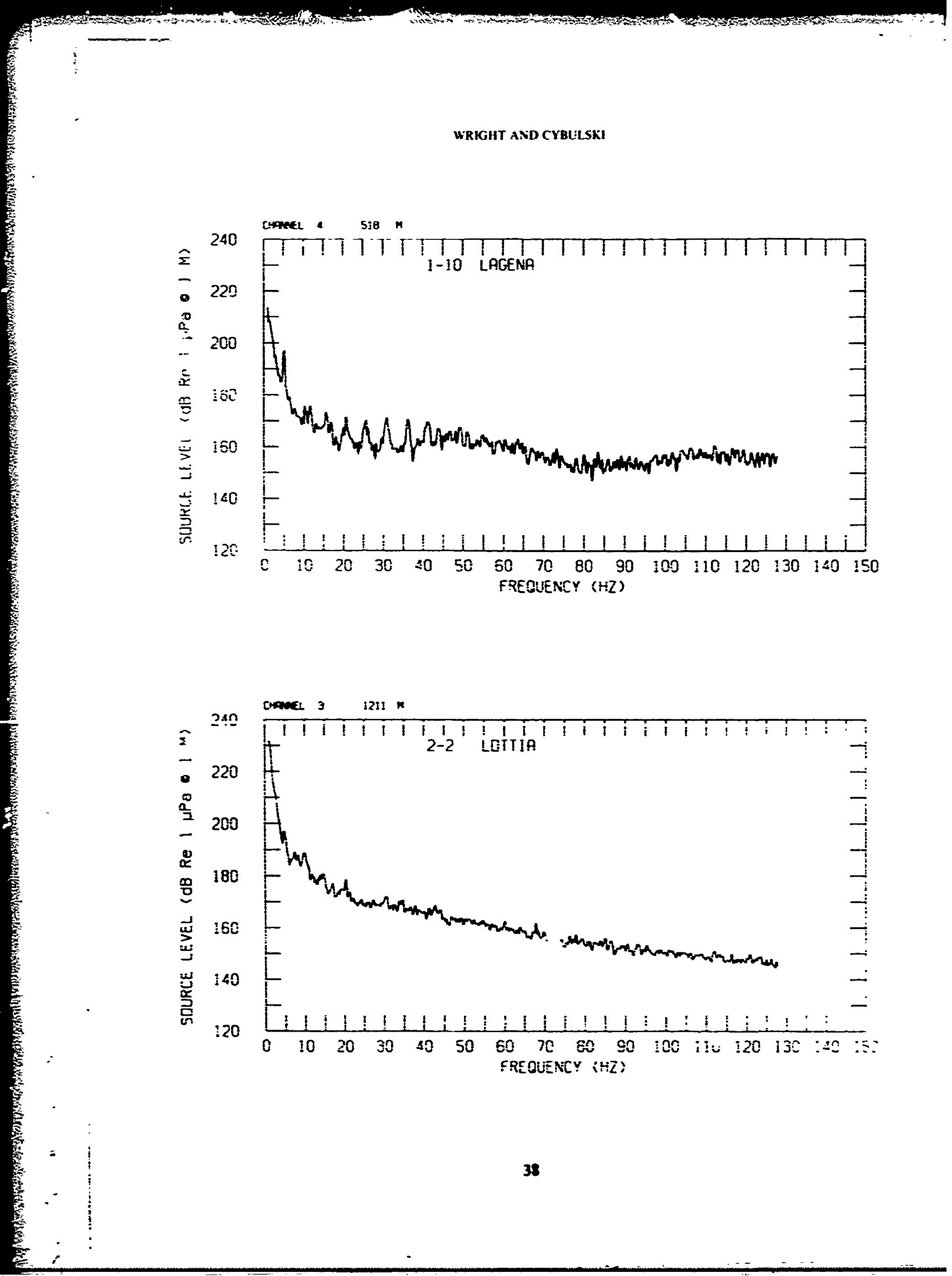




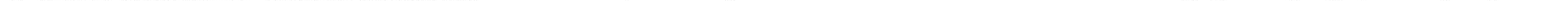



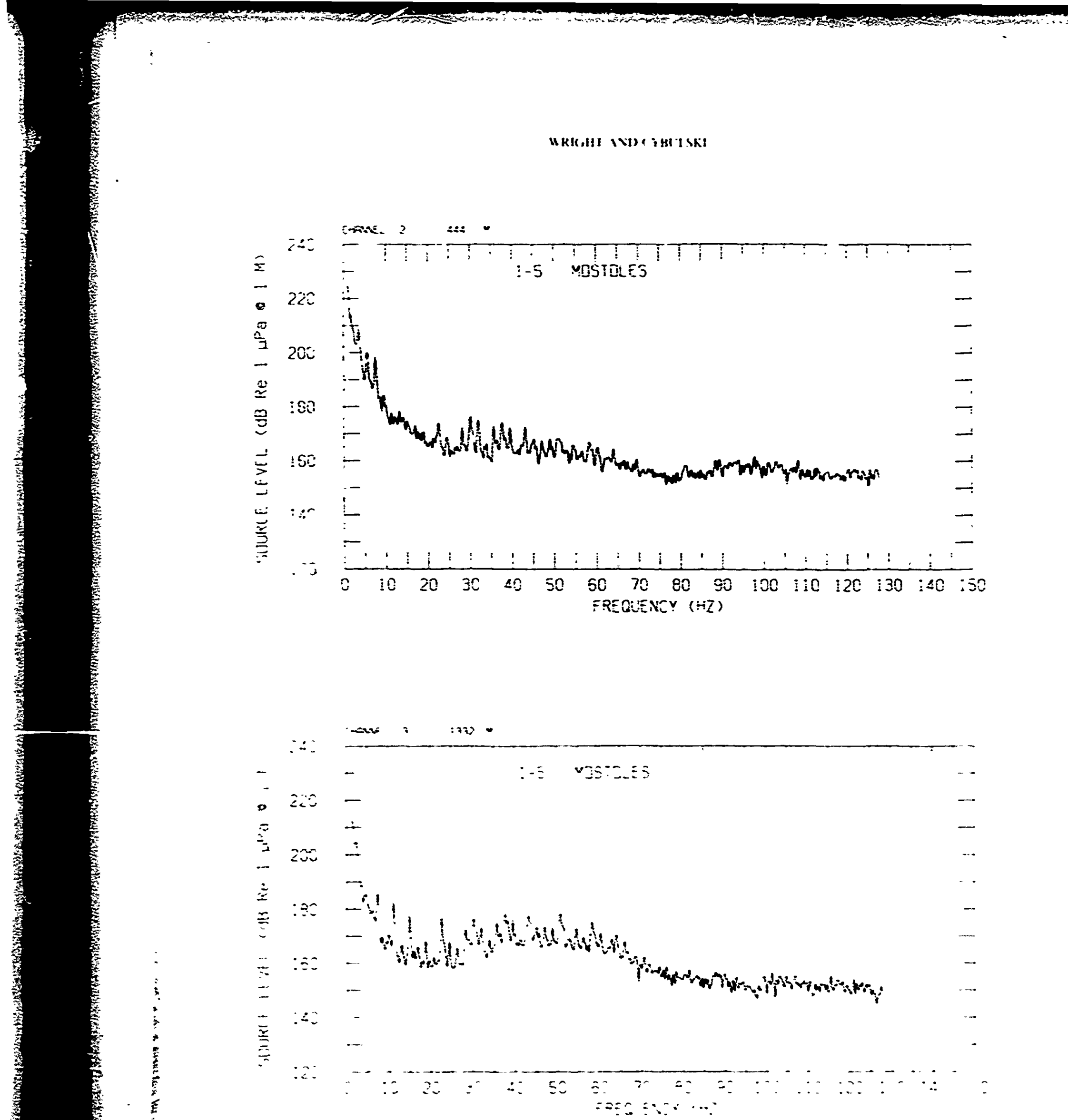
NRL REPORT 8677
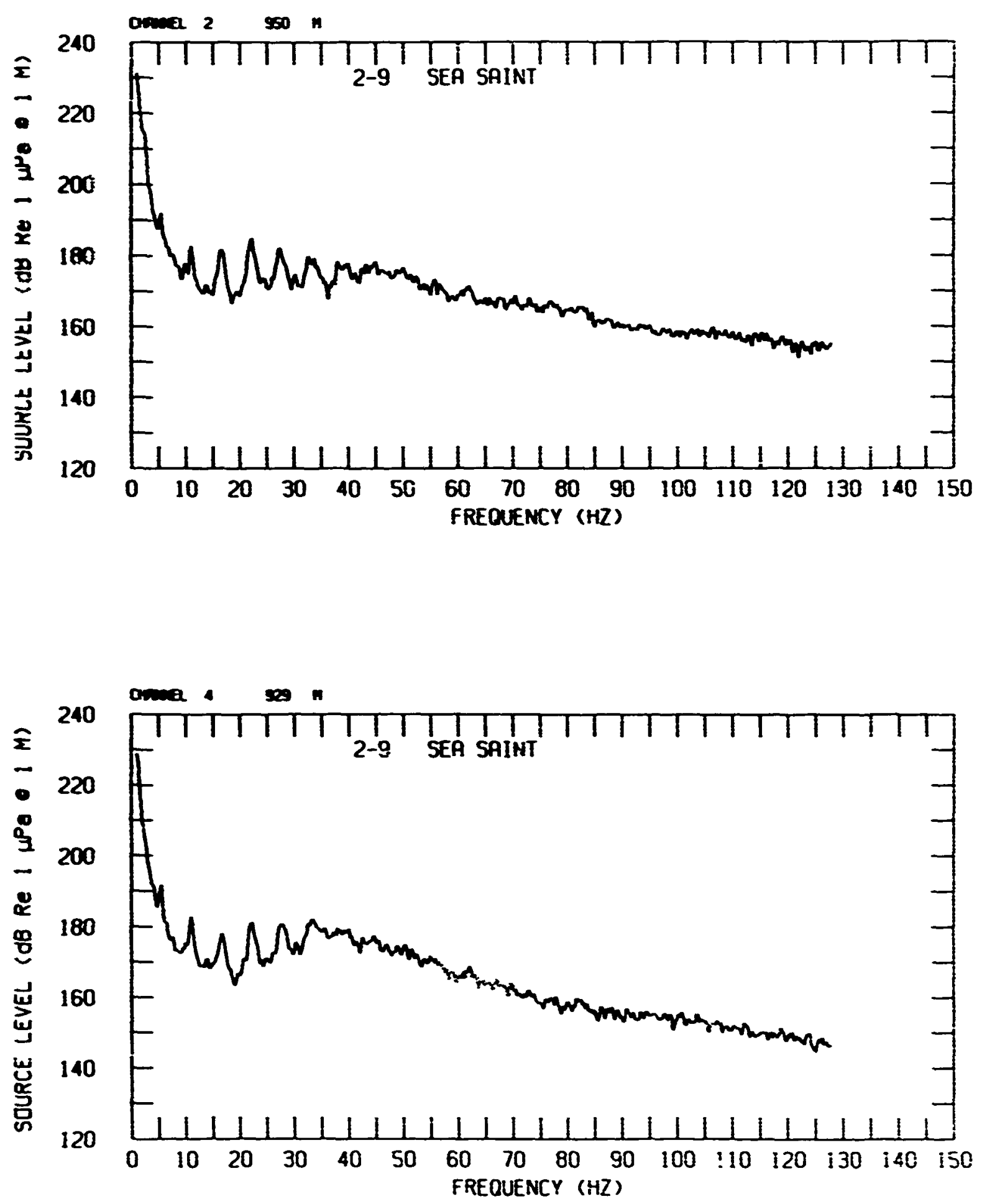

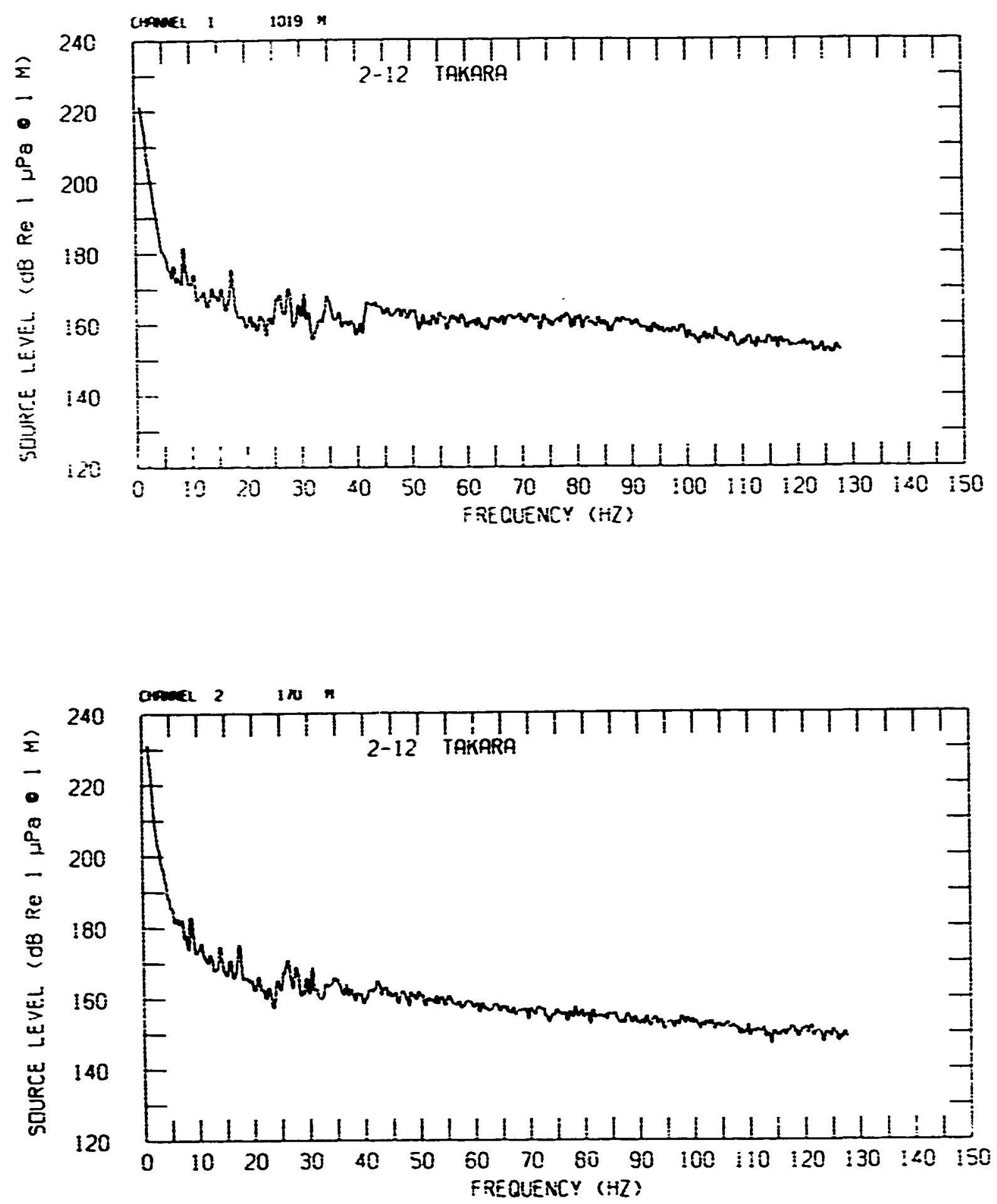

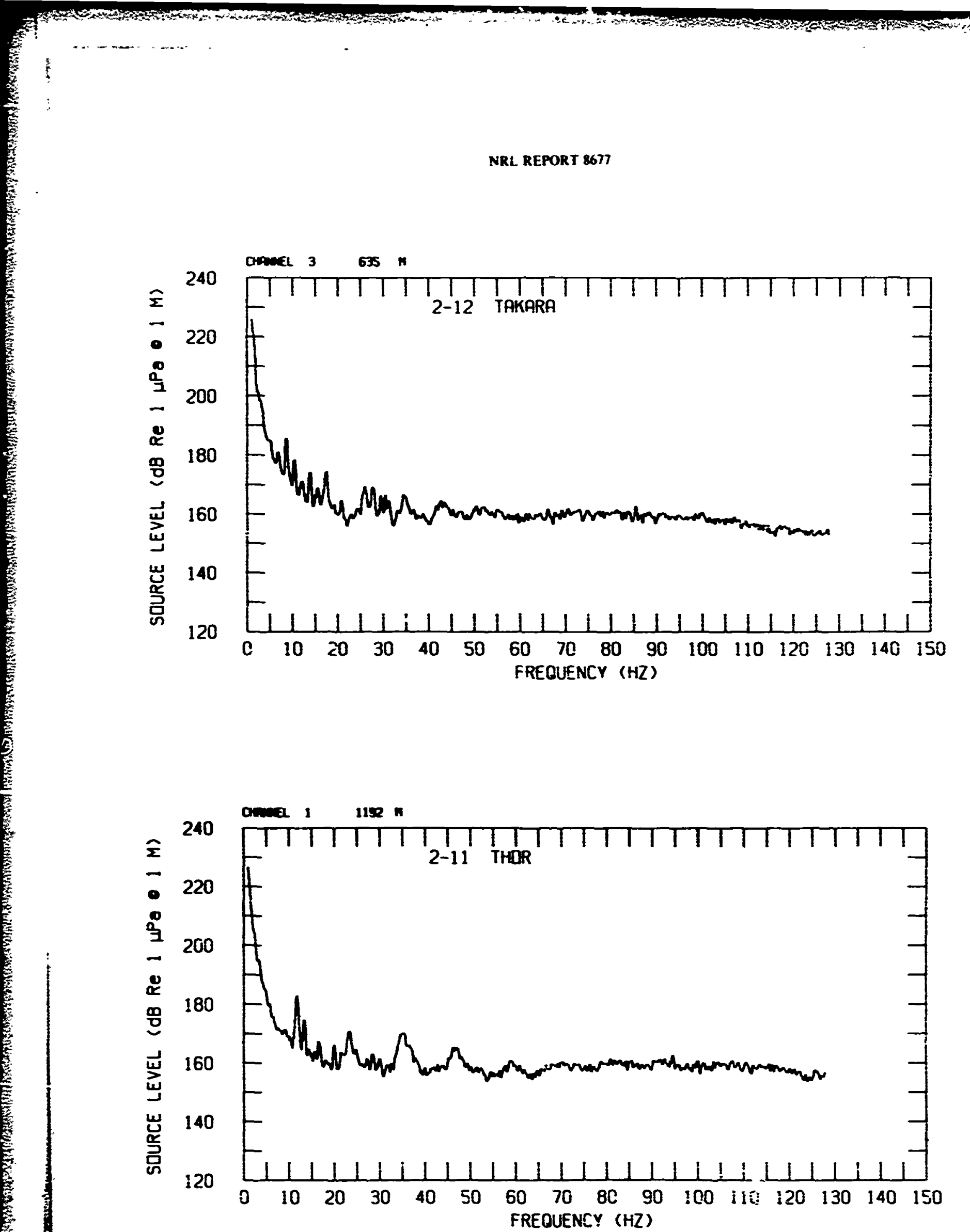

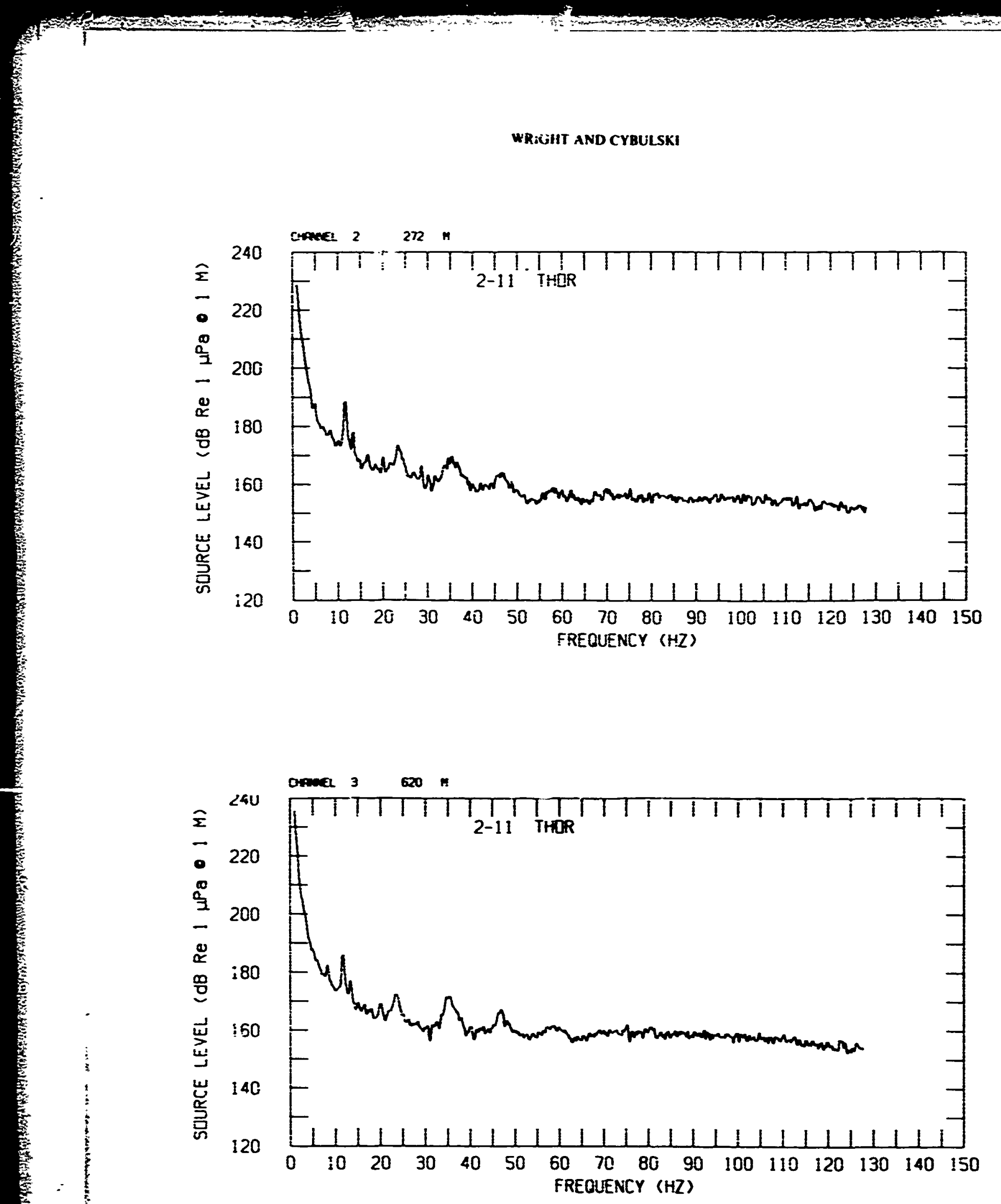

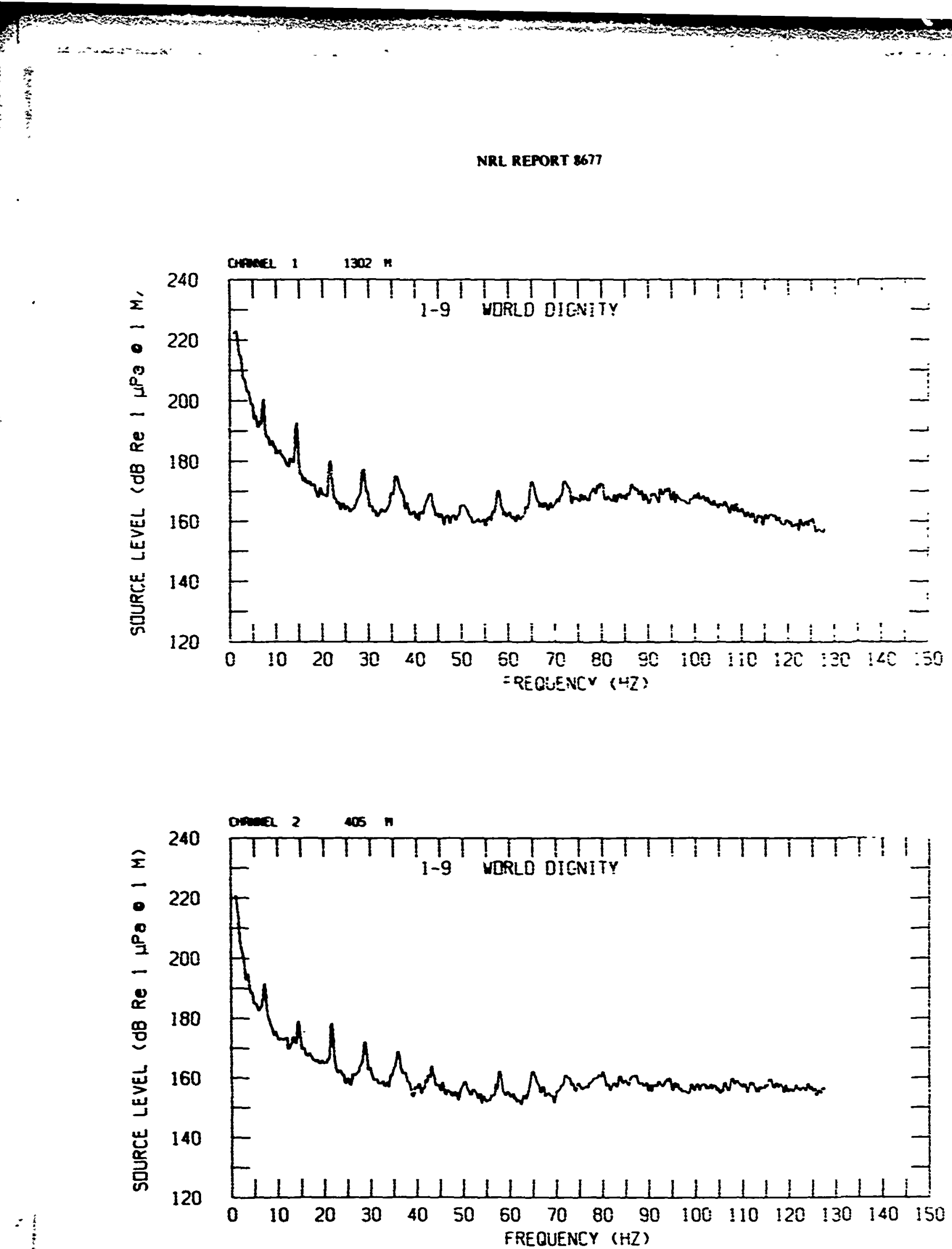

47 

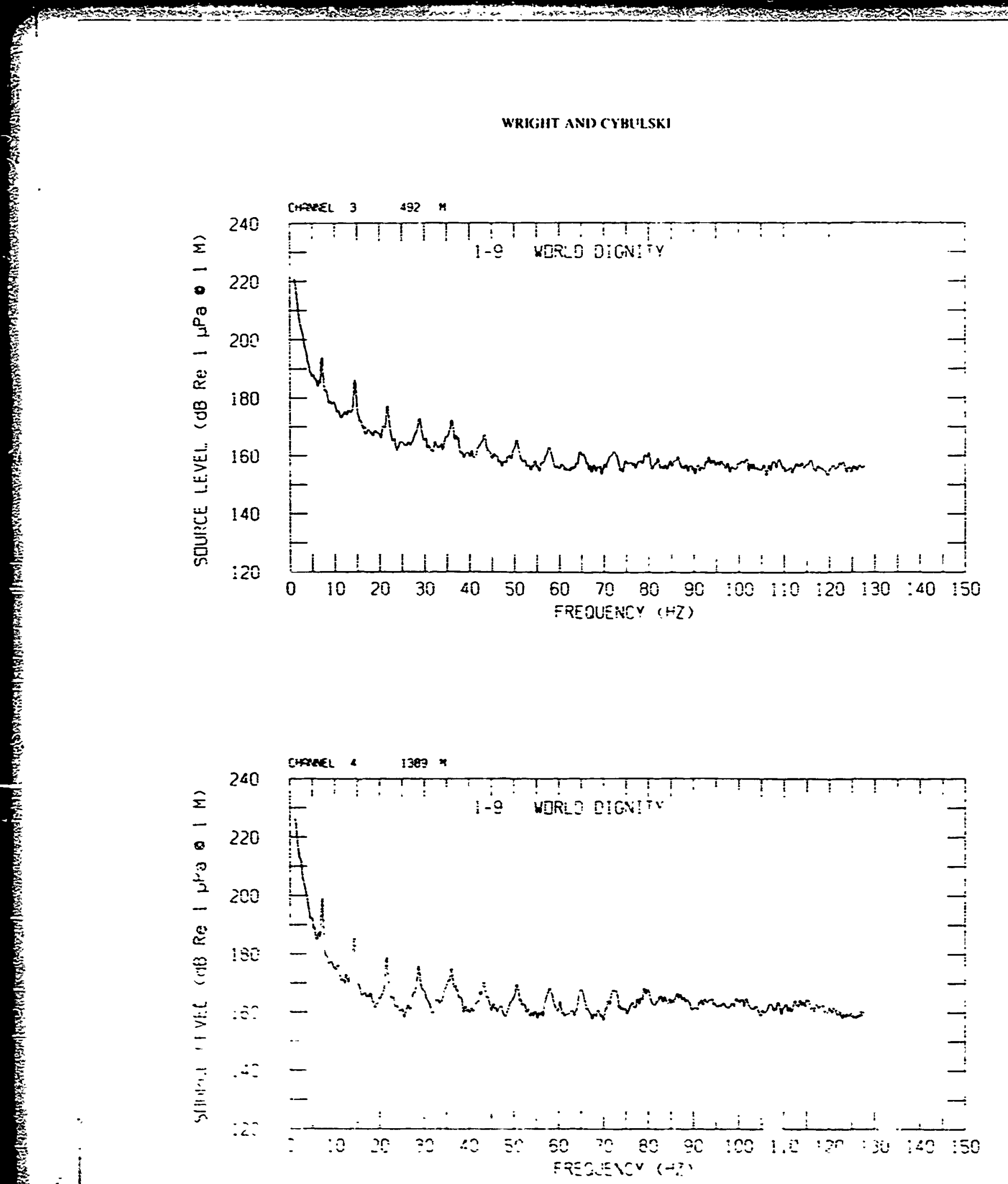


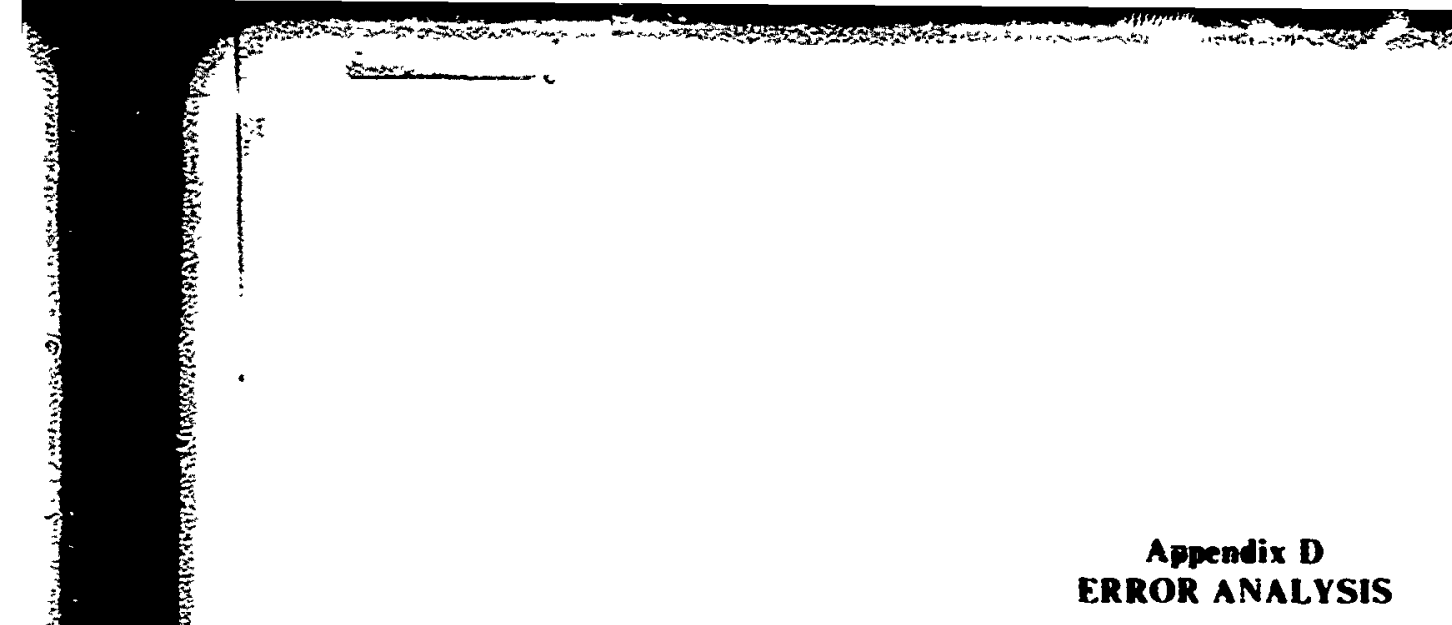

To assess the relative inportance of errors in the various measured and estimated parameters used in computing acoustic solirce level, we derive some propagation-of-error equations in these parameters. The general technique is:

- Express the camputed quantity as a function of the statistically independent variables.

- Compute its total differential as a function of the differential of these independent variables.

- Square this equation and substitute standard exrors in the variables for differentials, assuming cross-terms in statistically independent errors vanish in the mean.

First, define a set of symbols for the independent variables and their standard errors:

\begin{tabular}{|c|c|}
\hline - Source deplh (m) & $y_{s}$ \\
\hline - Receiver depih (m) & $y_{k}$ \\
\hline - Receiver spacing (m) & $\boldsymbol{D}$ \\
\hline - Ship speed $(\mathrm{m} / \mathrm{s})$ & $v$ \\
\hline - Observation time (s) & $t$ \\
\hline - Time of CPA (s) & $t_{0}$ \\
\hline $\begin{array}{l}\text { - Peraivar laval ar hyirnnghnne } \\
\text { with calibration error (dB) }\end{array}$ & $R L_{\alpha}$ \\
\hline $\begin{array}{l}\text { - Peak estimate of } R L \\
\text { with measurement error (dB) }\end{array}$ & $R L_{k}^{*}$ \\
\hline
\end{tabular}

Also define some symbols for derived quantities, with their standard errors:
- Source-receiver slant range ( $\mathrm{m}$ )
$r \quad S_{r}$
- Range to buoy $k$ at closest approach $(m) \quad x_{k} \quad S_{x t}$
- Source level (dB)
$S L \quad S_{L}$

Next. we show the computation of the range at CPA for one of the closest buoys, and compute its standard error. under the general assumpion that the ship constitutes an omnidirectional foint source. and passes between buoys 1 and 2 with $200 \mathrm{~m} \leq x_{0}, x_{2} \leq 1200 \mathrm{~m}$. For frequencies below $20 \mathrm{~Hz}$. the Iransmission loss is then on the $\mathbf{4 0} \mathrm{log} r$ portion of the Lloyd-mirror curve. and we can write approximately

$$
R L_{L}=S L-T L_{0}\left(y_{3} . y_{R} . S\right)-i \log r_{A} . \text { where } c=40 .
$$

Now

$$
r_{i}^{2}=x_{k}^{2}+h^{2}+v^{2}\left(t-t_{0}\right)^{2} \text {. where } h=y_{R}-y_{S} .
$$


Put $\xi=\eta^{2}-1$, where

$$
\eta \equiv\left[\frac{x_{2}^{2}+h^{2}}{x_{i}^{2}+h^{2}}\right]^{1 / 2}=10^{\left(R L_{i}-R L_{2}\right) / c}
$$

i.e. $\boldsymbol{\eta}$ is the slant-range ratio for buoys 1 and 2 at CPA. Then solving for $x_{1}$.

$$
\left.x_{1}=\frac{1}{!} \mathrm{i} \sqrt{(\xi+1) D^{2}-\xi^{2} h^{2}}-D\right] .
$$

The standard error for $x_{1}$ can then be (...... sted by

$$
S_{x_{i}}^{2}=\left[\frac{D^{2}-2 \xi h^{2}}{2 \xi\left(\xi x_{1}+D i\right.}-\frac{x_{1}}{\xi}\right]^{2} S_{\xi}^{2}+\left\lfloor\frac{\left(D-x_{1}\right)}{\xi x_{1}+D}\right]^{2} S_{\bar{D}}^{2}+\frac{\xi^{2} h^{2}}{\left(\xi x_{1}+D\right)^{2}} S_{\dot{S}}^{2}+\frac{(\xi+1) h^{2}+h^{2}}{\left(\xi x_{1}+D\right)^{2}} S_{k}^{2} .
$$

where, for convenience, the coefficients are in terms of $\xi$ and $x_{1}$, as defined above, and

$$
S_{\xi}^{2}=\left(\frac{2 \text { in } 10}{c}\right)^{2}(\xi+1)^{2}\left(S_{1}^{2}+S_{1}^{2}+S_{2}^{2}+S_{2}^{2}\right) \text {. }
$$

Note that the receiver depths of buoys 1 and 2 are treated as statistically independent in the differentiation step.

A general equation for the standard error on source level, as a function of time $t$ and slant range $r$ (or, equivalently, aspect angle?, is derived from

$$
\begin{aligned}
& S L=R L+\pi L \\
& d S L=d R L+\frac{\partial T L}{\partial r} d r+\frac{\partial T L}{\partial y_{S}} d i s_{s}+\frac{\partial T L}{\partial y_{R}} d_{k} . \\
& S_{i}^{2}=\left\{1+\left.\frac{2 x_{1}}{2}\left|\frac{\xi+1}{\xi}\right|\left[\frac{D^{2}-2 \xi h^{2}}{2\left(\xi r_{i}+n\right)}-x_{1}\right)\right|_{j} ^{2} S_{i}^{2}\right. \\
& +\left.\left\{\frac{2 x_{1}}{r^{2}}\left(\frac{\xi+1}{\xi}\right) \mid \frac{D^{2}-2 \xi h^{2}}{2\left(\xi x_{1}+D\right)}-x_{1}\right)\right|^{2}\left(S_{1}^{2}+S_{i}^{2}+S_{2}^{2}\right) \\
& +\left[\frac{c}{2 y_{5} \ln 10}+\left.\frac{c x_{1}}{r^{2} \ln 10} \cdot \frac{\xi h}{\xi x_{1}+D}\right|^{2} S_{5}^{2}+\mid \frac{c x_{1}}{r^{2} \ln 10}\right)^{2}\left(\left.\frac{D-x_{1}}{\xi x_{1}+D}\right|^{2} S_{D}^{2}\right. \\
& +\left\{\left|\frac{c}{2 y_{k} \ln 10}-\frac{c x_{1}}{r^{2} \ln 10} \cdot \frac{(\xi+1) h}{\xi x_{1}+D}\right|^{2}+\left[\left.\frac{c x_{1}}{r^{2} \ln 10} \cdot \frac{h}{\xi x_{1}+D}\right|^{2}\right\} S_{k}^{2}\right. \\
& +\left(\frac{c v}{t^{2} \ln 10}\right)^{2}\left(t-t_{0}\right)^{2} S_{i}^{2}+\left(\frac{c v^{2}}{r^{2} \ln 10}\right)^{2}\left(t-t_{0}\right)^{2}\left(S_{i}^{2}+S_{0}^{2}\right) .
\end{aligned}
$$

wh e we have used

$$
\frac{\partial T L}{\partial y_{s}}=\frac{c}{2 y_{s} \ln 10} .
$$




$$
\begin{aligned}
& \frac{\partial T L}{\partial y_{R}}=\frac{c}{2 y_{R} \ln 10} . \\
& \frac{\partial T L}{\partial r}=\frac{c}{r \ln 10} .
\end{aligned}
$$

As a numerical example, for the ship Lagena at CPA we insert the following values for the observable parameters and estimates of their standard errors:

$$
\begin{array}{llll}
D=948 \mathrm{~m} & S_{D}=34 \mathrm{~m} & x_{1}=430 \mathrm{~m} & S_{i}=0.5 \mathrm{~s} \\
y_{S}=12 \mathrm{~m} & S_{S}=2.3 \mathrm{~m} & x_{2}=518 \mathrm{~m} & S_{0}=3.1 \mathrm{~s} \\
y_{R}=305 \mathrm{~m} & S_{R}=3.0 \mathrm{~m} & S_{1}=S_{2}=2.1 \mathrm{~dB} & \\
v=7.5 \mathrm{~m} / \mathrm{s} & S_{v}=0.1 \mathrm{~m} / \mathrm{s} & S_{1}^{\prime}=S_{2}^{j}=0.5 \mathrm{~dB} &
\end{array}
$$

The first few terms of the formula are evaluated as:

$$
S_{L}^{2}=1.01 \mathrm{~dB}^{2}+1.33 \mathrm{~dB}^{2}+2.79 \mathrm{~dB}^{2}+\ldots
$$

so that, under these assumptions, hydrophone calibration error and suurce depth estimation error each contribute about $1.5 \mathrm{~dB}$ to the measurement error. The rest of the terms are negligible. 